\title{
Vibrational analysis of cyclo(b-Ala-L-Ala) in two crystalline forms. Effect of structure on peptide group and $\mathrm{CH}$ modes*
}

\author{
T. C. ChEAM and S. KRIMM \\ Biophysics Research Division and Department of Physics, University of Michigan, $\mathrm{nnn}$ Arbor, MI 48109 , \\ U.S.A.
}

(Received 8 May 1987; in final form 27 June 1987; accepted 29 June 1987)

\begin{abstract}
Cyclo(D-Ala-L-Ala) has been found by X-ray diffraction to crystallize in two forms with different hydrogen bond patterns and strengths and different conformations of the $\mathrm{C}^{\alpha} \mathrm{H}^{\alpha} \mathrm{C}^{\beta} \mathrm{H}_{3}$ group. We have done a comprehensive analysis of the Raman and i.r. spectra of both forms and their $\mathrm{N}$-deuterated derivatives. Spectra were taken of oriented single crystals, polycrystalline powders, and aqueous solutions, allowing a virtually complete vibrational assignment. Systematic, distinct differences were observed in the modes of the $\mathrm{CONH}$ group and in the $\mathrm{CH}$ stretching and bending modes. These spectral differences have been correlated with the different molecular and crystal structures. In particular, the width and sub-band structure of the $\mathrm{NH}$ stretch mode and the splittings of the $\mathrm{CO}$ stretch are shown to be related to the hydrogen bond pattern, and the $\mathrm{NH}$ bend modes are found to be relatively as sensitive to the hydrogen bond strength as is the NH stretch. The differences in the $\mathrm{CH}^{2}$ bend modes show that both conformations exist in solution. Ab initio molecular orbital calculations have been done to understand the frequency shifts of the $\mathrm{NH}$ and $\mathrm{CH}^{\alpha}$ stretch modes in the two forms. Normal mode calculations were also done.
\end{abstract}

\section{INTRODUCTION}

We have previously described a comprehensive analysis of the Raman and i.r. spectra of cyclo(Gly-Gly) and five of its isotopic derivatives $[1,2]$. In this paper we report on a study of the next simplest cyclic peptide, cyclo (D-Ala-L-Ala).

Besides further elucidating the modes characteristic of the cis peptide group, cyclo(D-Ala-L-Ala) is especially interesting in its own right. This compound has been found to crystallize in two forms with very different hydrogen bonding configurations (Fig. 1). In one, which we will designate as form I following SLETTEN [3], the molecules form hydrogen-bonded layers $[4,5]$, whereas in form II hydrogen-bonded chains similar to those in cyclo(Gly-Gly) are present [3]. In addition, the dimensions of each $\mathrm{N}-\mathrm{H} \ldots$ $\mathrm{O}=\mathrm{C}$ group (Fig. 1) suggest that the hydrogen bonds in II are stronger than those in $\mathbf{I}$. We will see that the different hydrogen bond patterns and strengths result in systematic differences in the spectra of the two forms, thus shedding light on the sensitivity of various modes to hydrogen bonding. We have recently studied by $a b$ initio molecular orbital methods the changes in the harmonic force constant and i.r. intensity of the peptide NH stretch mode as a function of hydrogen bond geometry [6]. Similar calculations for the other peptide group modes would be much more difficult because these modes are more delocalized. Cyclo(DAla-L-Ala) provides a very convenient system where the effects of hydrogen bond geometry on these other modes, as well as on the $\mathrm{NH}$ stretch, can be studied experimentally. Though the peptide groups in cyclo (D-

*This is paper number 37 in a series, "Vibrational analysis of peptides, polypeptides, and proteins".
Ala-L-Ala) are in the cis conformation, our results should provide at least a qualitative guide in studying the modes of trans peptides.

Furthermore, the methyl side chains are more nearly axial in I than in II; conversely, the $\mathrm{CH}^{\alpha}$ bond is more nearly axial in II (Fig. 1). We find distinct differences between $\mathbf{I}$ and $\mathbf{I I}$ in the frequencies and intensities of the $\mathrm{CH}^{\alpha}$ stretching and bending modes and the $\mathrm{CH}_{3}$ antisymmetric stretches, suggesting a correlation of these modes with the conformation of the $\mathrm{CH}^{\alpha} \mathrm{CH}_{3}$ group.

Much less work has been done on cyclo(D-Ala-LAla) than on cyclo(Gly-Gly). BROCKMANN and Musso [7] recorded the i.r. spectrum of form I, and STEIN [8] measured i.r. and Raman spectra, also of I. Only a partial assignment was given by these workers. We will present the results of Raman and i.r. studies of I and II and their $\mathrm{N}$-deuterated derivatives, and of normal mode calculations of the crystals. Our data and calculations have allowed a nearly complete vibrational assignment of cyclo(D-Ala-L-Ala), with tentative assignments only for the methyl torsion mode and for the far i.r. region. Ab initio calculations were also done to understand some of the observations.

\section{EXPERIMENTAL}

The cyclo(D-Ala-L-Ala) was synthesized by ANITA Go in Prof. K. D. KopplE's laboratory. Crystals were grown by slow evaporation from aqueous solution. Form I grows as chunky crystals at room temp., and form II as thin platelets at higher temperatures (we used $50-70^{\circ} \mathrm{C}$ ). We found it easier to get form II than form I. The $\mathrm{N}$-deuterated materials were obtained from $\mathrm{D}_{2} \mathrm{O}$ solution, but we were unable to grow single crystals of $\mathbf{I}-$ ND. Single-crystal films for polarized i.r. studies were prepared by cleaving from thicker pieces.

Spectra were run with a Spex 1403/Datamate system with excitation from the $514.5 \mathrm{~nm}$ line of a Spectra Physics 165 

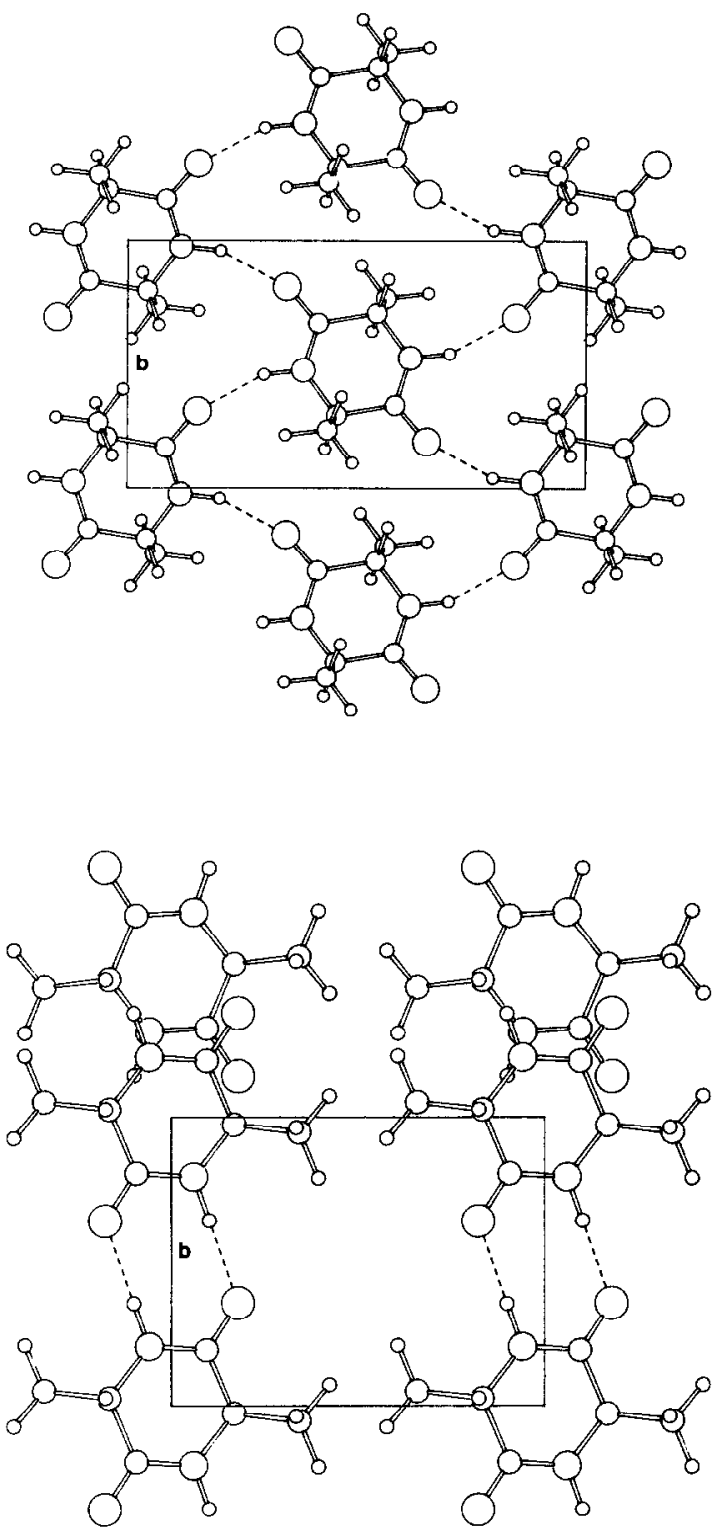

Fig. 1. Cyclo(D-Ala-L-Ala) crystal structures. Top: Form I, space group $P 2_{1} / n$. Viewed perpendicular to (101). Hydrogen bond dimensions: $\quad \mathbf{R}(\mathrm{N} \cdots \mathrm{O})=2.866 \AA, \quad \mathbf{R}(\mathrm{C}=\mathrm{O})$ $=1.236 \AA, \theta(\mathrm{HNO})=15.0^{\circ}, \theta(\mathrm{CON})=146.0^{\circ}$. Bottom: Form II, space group $P 2_{1} / c$. Viewed along $c$ axis. Hydrogen bond dimensions: $R(N \cdots O)=2.859 A, \quad R(C=O)$ $=1.241 \AA, \theta(\mathrm{HNO})=3.6^{\circ}, \theta(\mathrm{CON})=124.1^{\circ}$.

argon ion laser, and on a Bomem DA3 Fourier transform i.r. spectrometer. The bandpass in the Raman experiments on powders and single crystals was $1-2 \mathrm{~cm}^{-1}$ with laser powers of about $300 \mathrm{~mW}$ at the sample. The i.r. powder spectra were run at $1 \mathrm{~cm}^{-1}$ resolution in the $4000-400 \mathrm{~cm}^{-1}$ region and at $2-4 \mathrm{~cm}^{-1}$ below $400 \mathrm{~cm}^{-1}$; the spectrometer was evacuated to less than 2 torr. Powder spectra at liquid nitrogen temperature were obtained using an Air Products LT-3-110 cryostat and homemade cells. I.r. spectra of powdered samples were run in $\mathrm{KBr}$ pellets and, below $300 \mathrm{~cm}^{-1}$, as pressed films. For the Raman spectra, the powder was packed into glass capillaries. Solution spectra at room temperature were taken using standard i.r. liquid cells and glass capillaries.
The single-crystal spectra were run with (101) sections of I and with (100) sections of II, these faces being cleavage planes. Since both forms are monoclinic, the extinction directions in each specimen are along and perpendicular to $b$. The Cartesian axes and polarization directions used in our work are defined as follows. In I, $y$ is parallel to $b$ and $z$ perpendicular to (101); in II, $y$ is also parallel to $b$ and $z$ is along $c$. That is, in Fig. 1 the $x, y$, and $z$ axes are oriented in the conventional manner in each structure: $x$ horizontal, $y$ vertical, and $z$ out of the plane of the figure.

\section{NORMAL MODE CALCULATIONS}

The crystal structures of E. SLETTEN [5] and J. SLETTEN [3] were used. E. SLETTEN's X-ray determination of $I$ seems more reliable than the study by BENEDETTI et al. [4]. As we did for cyclo(Gly-Gly), we modified the $\mathrm{NH}$ and $\mathrm{CH}$ bonds given by J. SLETTEN for II to $1.00 \mathrm{~A}$ and $1.09 \mathrm{~A}$, respectively; we used similarly modified hydrogen atom positions given for I by E. SLETTEN.

The normal mode calculations were done in a Cartesian coordinate basis, and factoring of the secular equation for the crystals was based on KOBAYASHI's [9] method. Both crystal forms are monoclinic with two molecules per unit cell. In both forms the factor group is isomorphic to $C_{2 h}$ and four symmetry blocks result: $A_{\theta}, B_{\theta}, A_{u}$, and $B_{u}$, each of dimension $30 \times 30$ corresponding to the asymmetric unit $\left(\mathrm{CONHCHCH}_{3}\right)$.

The internal and local symmetry coordinates for the peptide group and alanyl residue are as given in [2] and [10], respectively. The intramolecular force field is a combination of the cyclo(Gly-Gly) set and the alkane field of [11]. The cyclo(Gly-Gly) force constants (Set II in [2]), which were refined in a non-redundant basis, were transformed into the local symmetry basis. The parameters relating to the peptide group were then transferred to cyclo(D-Ala-L-Ala). To this set were added force constants from [11] for the $\mathrm{CHCH}_{3}$ group, except that the $\mathrm{C}^{\alpha} \mathrm{C}^{\beta}$ torsion force constant was taken from $\beta$-poly(L-alanine) [10] because of the different definition of the torsional coordinate used in [11].

While we eventually intend to refine a force field for cyclo(D-Ala-L-Ala), our present calculations were done mainly to help in assigning the spectra. We have therefore not tried to adjust the force constants to get better agreement with observed frequencies, except for the $\mathrm{CH}_{3}$ stretch modes, which could be easily improved by modifying the diagonal $\mathrm{CH}$ force constant to 4.800 mdyne/ $\mathrm{A}$ (from 4.699) and the $\mathrm{CH}, \mathrm{CH}$ interaction term to $0.050 \mathrm{mdyne} / \mathrm{A}$ (from 0.043 ).

Intermolecular force constants were computed from the 6-12 atom-atom potential of MOMANY et al. [12] with a cut-off radius of $5 \mathrm{~A}$ and without linear terms in the Cartesian derivatives [9]. We assumed values of 0.12 and 0.15 mdyne/ $A$ for the hydrogen bond $\mathrm{H} \cdot \cdots \mathrm{O}$ interaction in I and II, respectively; the value for $\mathrm{II}$ is the same as for cyclo(Gly-Gly). On addition of the intermolecular terms, the deformation modes in- 
volving the $\mathrm{H}^{\alpha}$ and $\mathrm{CH}_{3}$ groups shift considerably and generally become in worse agreement with the data. Because the alkane force field was refined without taking into account non-bonded interactions, and since the peptide group modes shift less, we will report only the intramolecular frequencies calculated without the atom-atom terms. The lattice modes given are calculated with the complete intramolecular and intermolecular force field.

\section{SPECTRAL ASSIGNMENTS}

Our Raman and i.r. room temp. spectra of cyclo (D-Ala-L-Ala) are shown in Figs 2-14. By comparison with spectra of less pure samples, bands due to impurities were identified in the $\mathrm{N}$-deuterated mate-
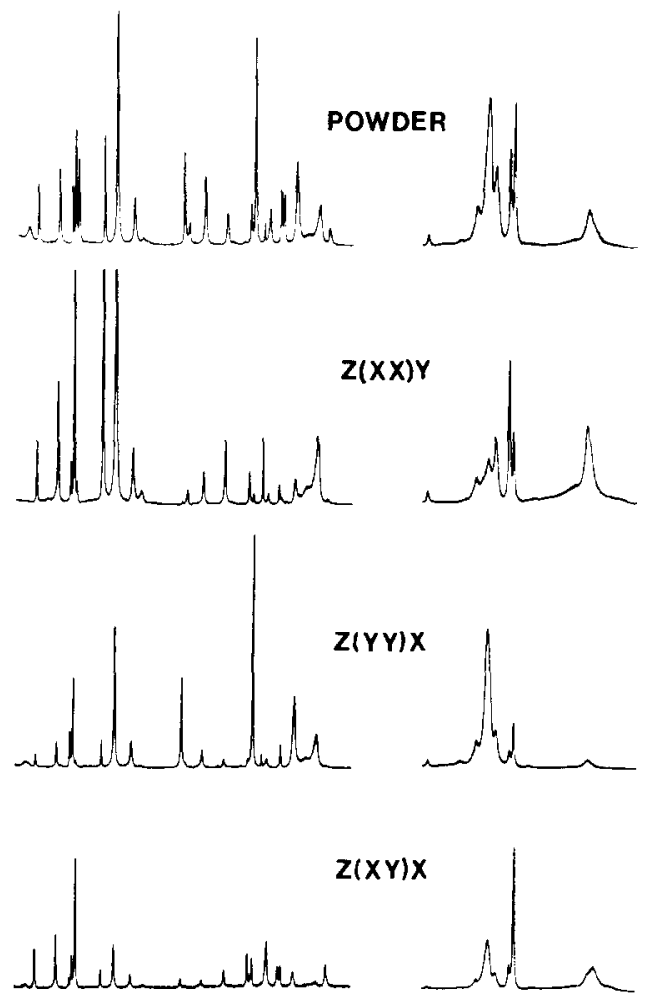

\section{$z(x z) x$}
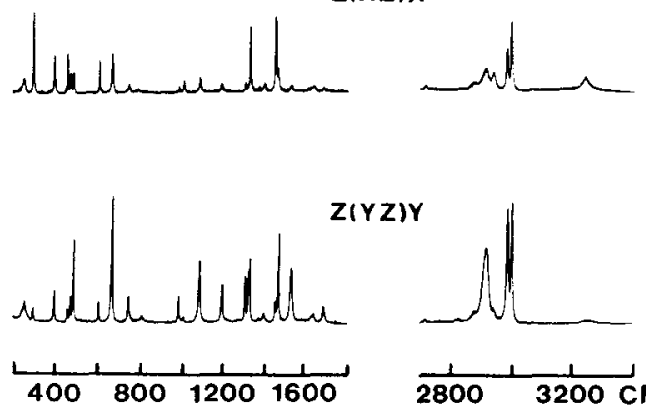

$Z(Y Z) Y$

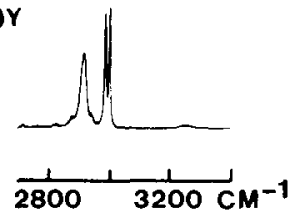

Fig. 2. Raman spectra of form I powder and single crystal. rials. Table 1 lists the observed frequencies and their assignments. Table 2 gives the calculated frequencies of an isolated type II molecule (of $C_{i}$ symmetry), and Table 3 shows the calculated lattice frequencies for the two crystal structures. For brevity, we list the calculated intramolecular modes for II and II-ND only; major differences in the results for I will be noted in the discussion. Figure 15 shows ORTEP plots of the atomic displacements for the intramolecular Ramanactive modes of II, and Figs 16 and 17 show the lattice modes of I and II.

With 20 atoms in a centrosymmetric molecule, there are 27 intramolecular modes in each of the four symmetry species. There are 6 Raman-active rotatory
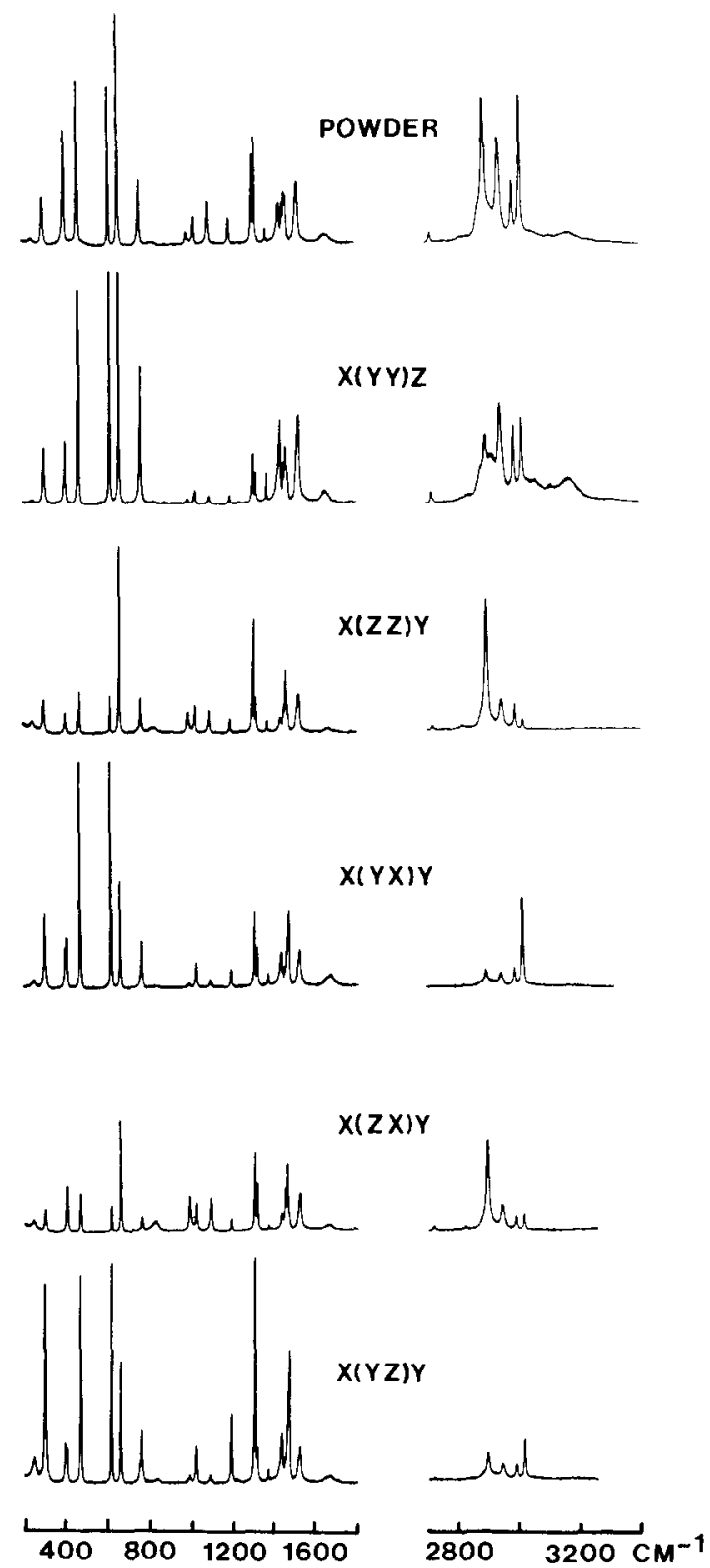

Fig. 3. Raman spectra of form Il powder and single crystal. 

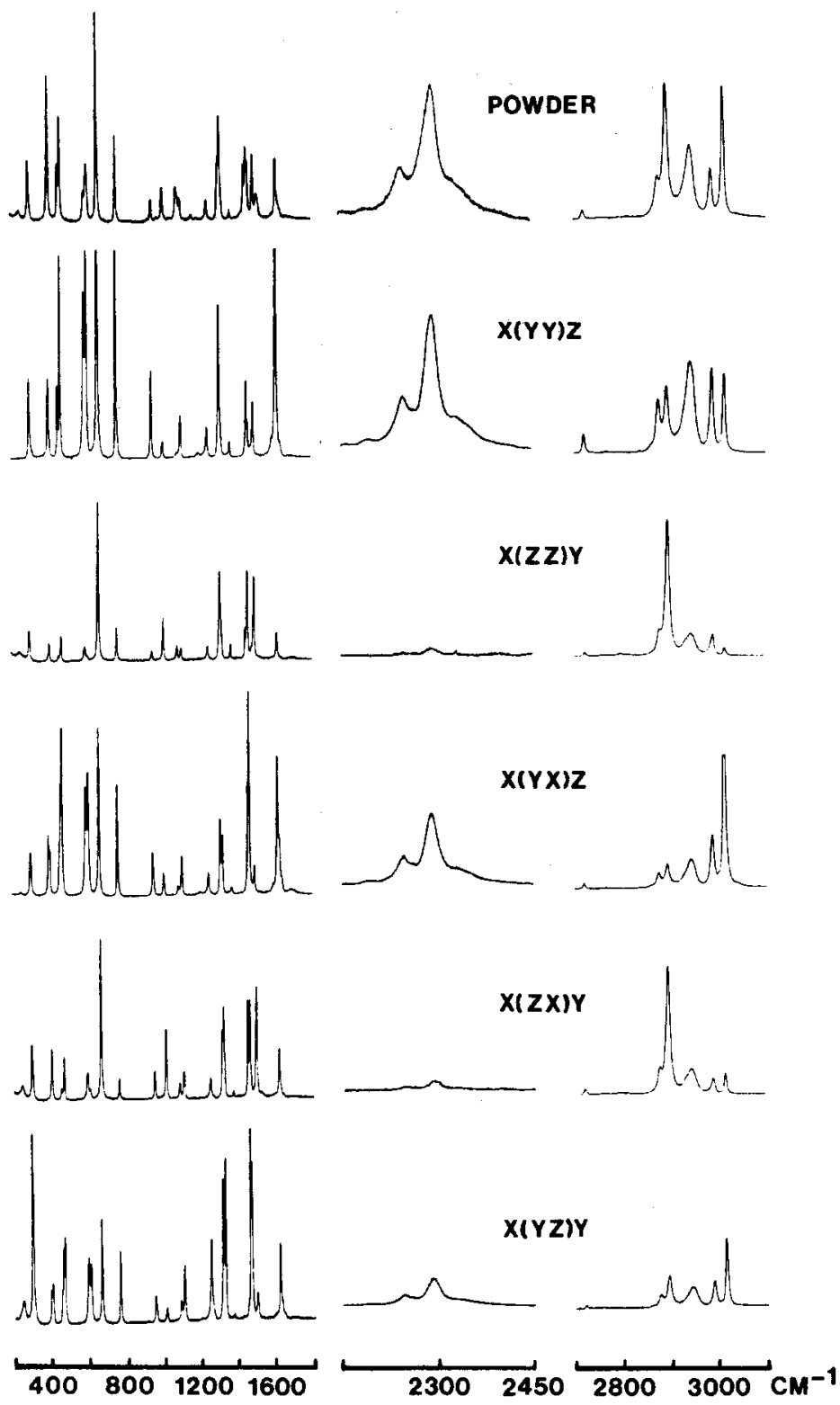

Fig. 4. Raman spectra of N-deuterated form II powder and single crystal.

lattice modes $\left(3 A_{g}+3 B_{g}\right)$ and 3 i.r.-active translatory lattice modes $\left(2 A_{u}+1 B_{u}\right)$. Where factor group splittings are observed, we have given the symmetry species for each component: bands of $A_{q}$ symmetry appear in the $x x, y y, z z$, and $x z$ spectra, whereas $B_{g}$ bands appear in the $x y$ and $y z$ spectra; $A_{u}$ bands are polarized parallel to $y$ and $B_{u}$ perpendicular. Though the ring atoms are very nearly co-planar [3-5], we have not tried to systematically classify the observed bands into in-plane and out-of-plane species because of the considerable inclination of the molecules to the $x-y$ plane, which we estimate to be $\sim 20^{\circ}$ in I and $\sim 25^{\circ}$ in II. In the rest of this section, we will discuss our spectral assignments. After having established the assignments, we can then discuss in more detail in the following sections the spectral differences between the two forms. In general, the peptide group and ring modes were quite easily identified by comparison with cyclo(Gly-Gly) and by $\mathrm{N}$-deuteration, and many of the side-chain modes were assigned by referring to analyses of $L$-alanine by other workers [13-15]. For reference, we note that the NH $\cdots$ OC dimensions in cyclo(Gly-Gly) are very close to those in II (Fig. 1$): R(N \cdots O)=2.853 \mathrm{~A}$, $\theta(\mathrm{HNO})=7.5^{\circ}, \theta(\mathrm{CON})=121.8^{\circ}[16]$.

Region above $2000 \mathrm{~cm}^{-1}$. The NH stretch (str) and four CH str modes (per symmetry species) are found in this region. As in cyclo(Gly-Gly), the NH str band is relatively stronger in the i.r. than in the Raman, whereas the $\mathrm{CH}$ stretches are much more prominent in the Raman. These bands show distinct differences in I and 1 I.

The NH str is easily assigned by N-deuteration. In I 

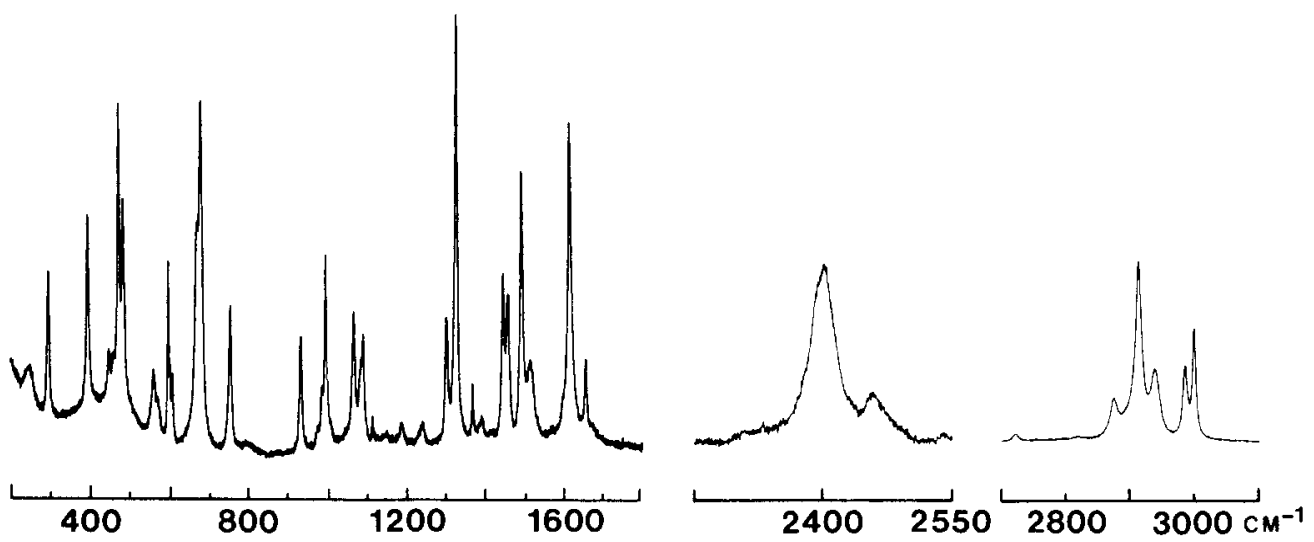

Fig. 5. Raman spectrum of $\mathrm{N}$-deuterated form I powder
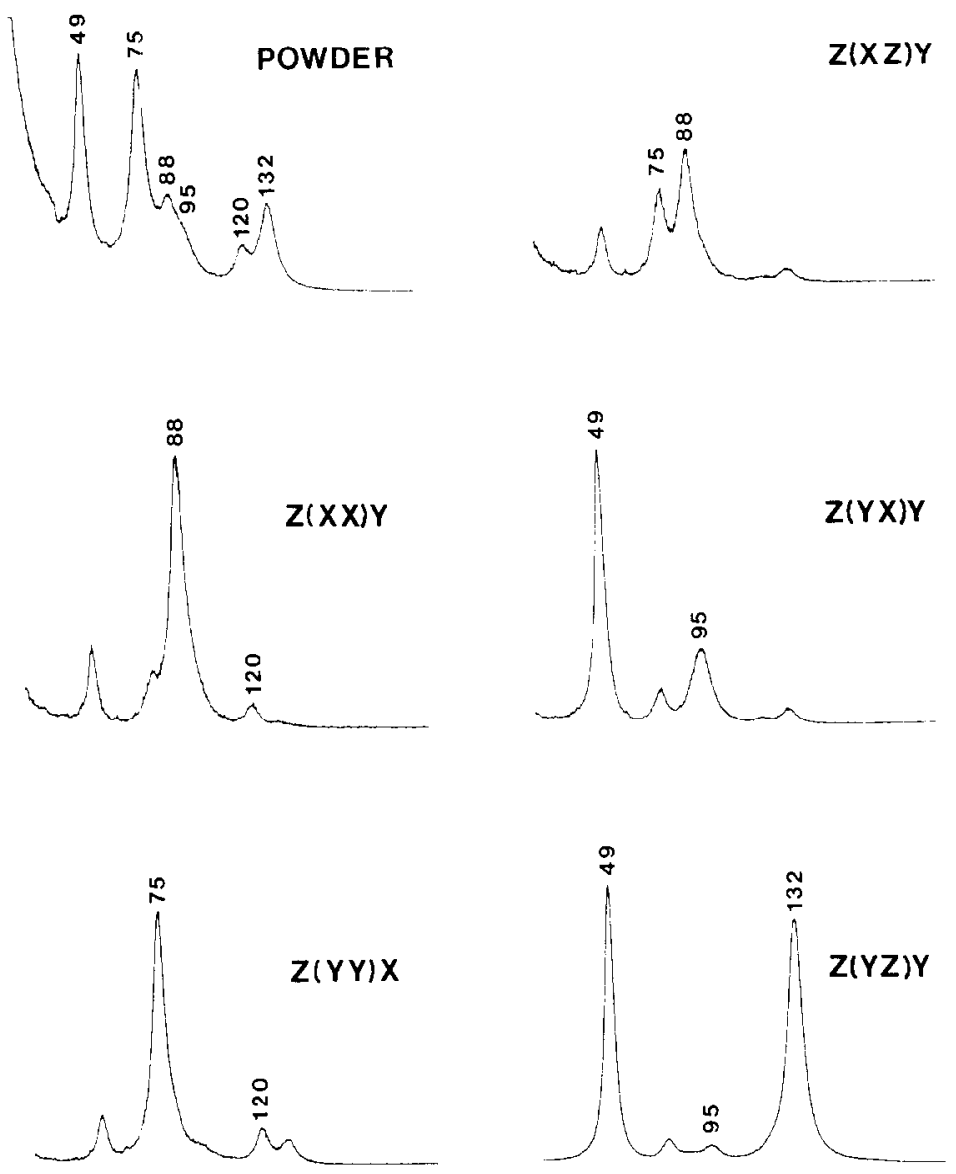

Fig. 6. Low frequency Raman spectra of form I powder and single crystal.

it forms a complex band with a main peak at $3247 \mathrm{~cm}^{-1}$ in the i.r. and $3239 \mathrm{~cm}^{-1}$ in the Raman. In its bandwidth and position, it is similar to the NH str band in $\alpha$-and $\beta$-poly(L-alanine) [17]. A shoulder at $3258 \mathrm{~cm}^{-1}$ on the Raman peak becomes more distinct at liquid nitrogen temperature, and is fully resolved in the $x y$ room temperature spectrum. Thus, whereas the main Raman peak is of $A_{g}$ symmetry, the $3258 \mathrm{~cm}^{-1}$ band is $B_{g}$, giving a factor group splitting of $19 \mathrm{~cm}^{-1}$ if we consider only these two peaks. Both shift down at low temperature (LT), by 8 and $5 \mathrm{~cm}^{-1}$, respectively; however, a weak $A_{g}$ band at $3193 \mathrm{~cm}^{-1}$ shifts up on cooling, to $3197 \mathrm{~cm}^{-1}$. The main i.r. peak also shifts down at LT by $11 \mathrm{~cm}^{-1}$ and sharpens appreciably, 

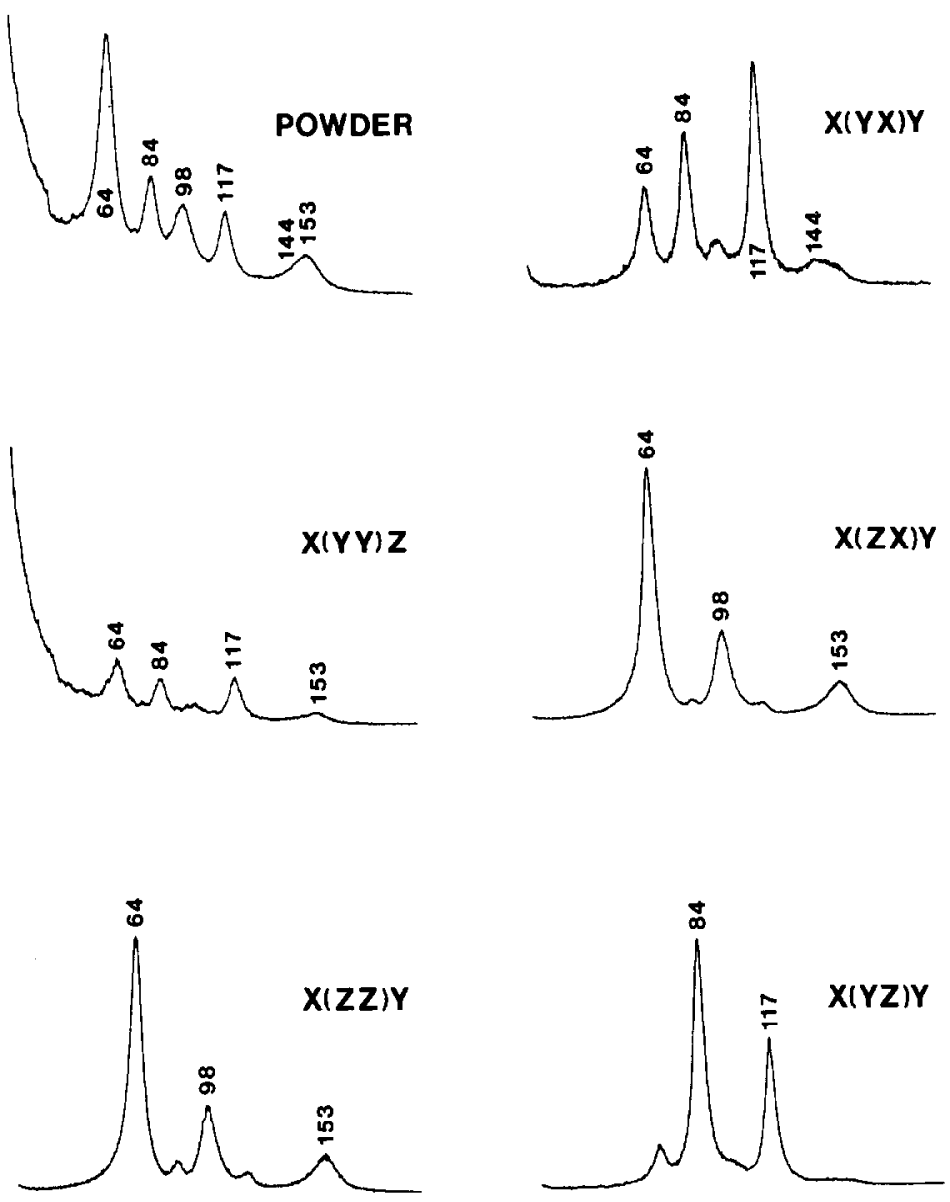

Fig. 7. Low frequency Raman spectra of form II powder and single crystal.
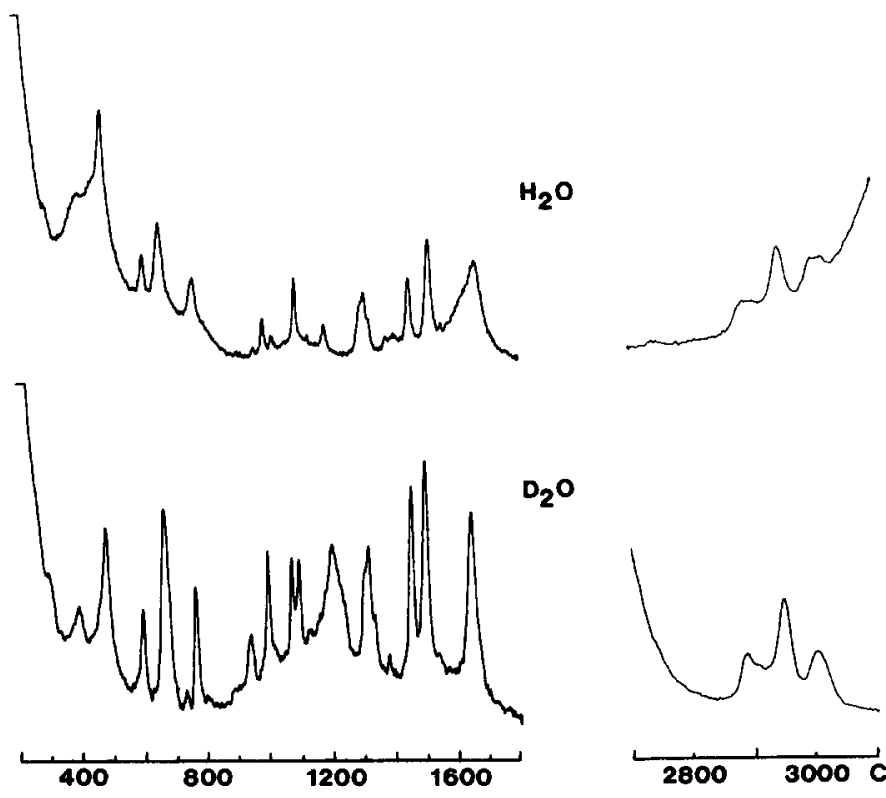

Fig. 8. Raman spectra of cyclo(D-Ala-L-Ala) in aqueous solution. 


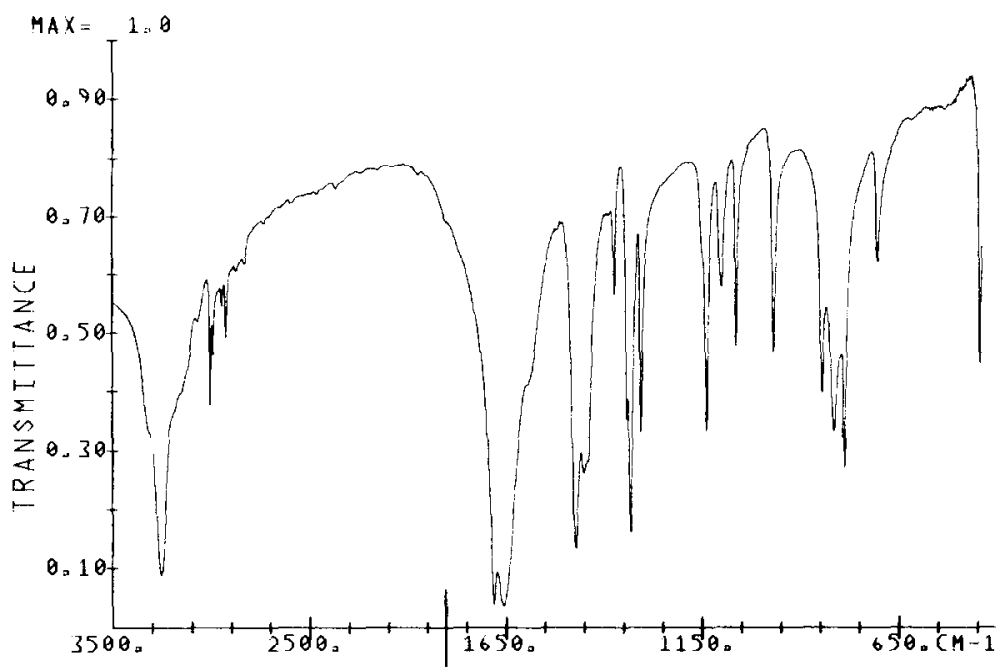

Fig. 9. I.r. spectrum of form I powder.

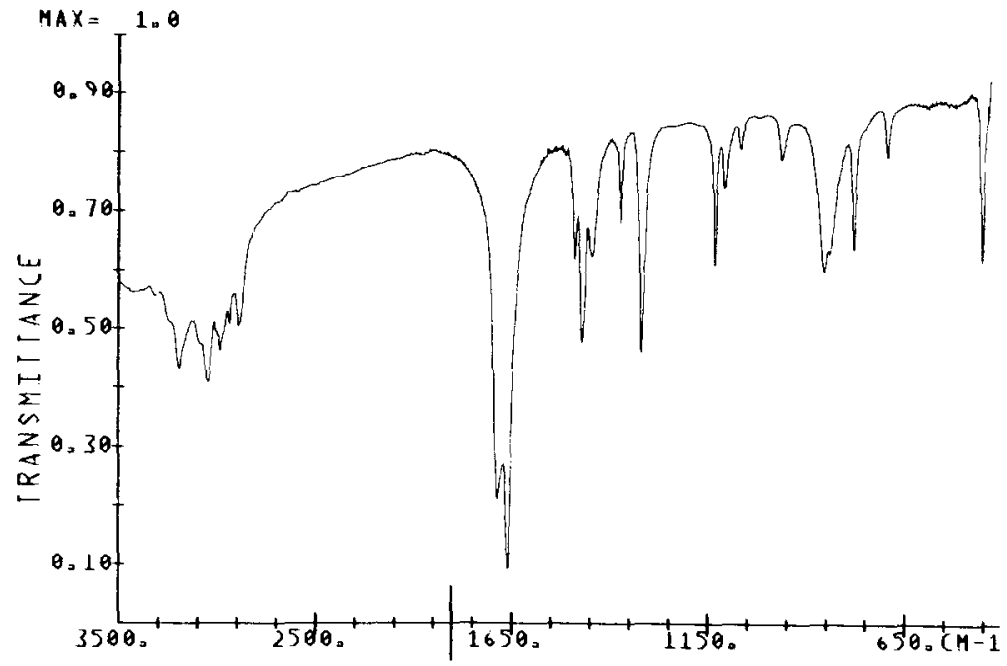

Fig. 10. I.r. spectrum of form II powder.

revealing a shoulder at $3222 \mathrm{~cm}^{-1}$. Several other subbands are observed in both i.r. and Raman even at room temperature. In the i.r. these are at 3178,3142 , 3109 , and $3058 \mathrm{~cm}^{-1}$, suggesting a progression with a spacing of about $40 \mathrm{~cm}^{-1}$.

The NH str band in II looks even more complex than in I and resembles closely that in cyclo(Gly-Gly). In the i.r., main sub-bands are found at 3192 and $3048 \mathrm{~cm}^{-1}$ (other sub-bands below $3000 \mathrm{~cm}^{-1}$ are weaker and difficult to distinguish from the $\mathrm{CH}$ stretches), and in the Raman broad, weak peaks are seen at 3164,3107 , and $3056 \mathrm{~cm}^{-1}$. By comparison, in cyclo(Gly-Gly) we observed sub-bands at 3192,3165 , and $3046 \mathrm{~cm}^{-1}$ in the i.r. and at 3160,3106 , and $3035 \mathrm{~cm}^{-1}$ in the Raman. Also as in cyclo(Gly-Gly), at LT the i.r. bands sharpen appreciably, revealing more fine structure, and both the
3192 and $3048 \mathrm{~cm}^{-1}$ peaks shift down by $10 \mathrm{~cm}^{-1}$. The Raman peaks are all strong in the $y y$ spectrum; in addition, this spectrum shows a broad feature near $2914 \mathrm{~cm}^{-1}$, among the $\mathrm{CH}$ str bands, that can be ascribed as part of the $\mathrm{NH}$ str complex in view of its similar polarization behavior and its absence in II-ND. Unlike in I and similar to cyclo(Gly-Gly), the $B_{g}$ spectra show peaks in essentially the same positions as in the $A_{g}$ spectra and with the same relative intensities. The strength of the NH str complex in the $x x$ spectrum in I and in the $y y$ spectrum in II is readily correlated with the direction of the NH bond in the two forms.

The ND str band is significantly narrower than the $\mathrm{NH}$ str, though again there is some fine structure. However, the difference in complexity between I and II is much less evident than for the NH str. In the i.r. in I, 


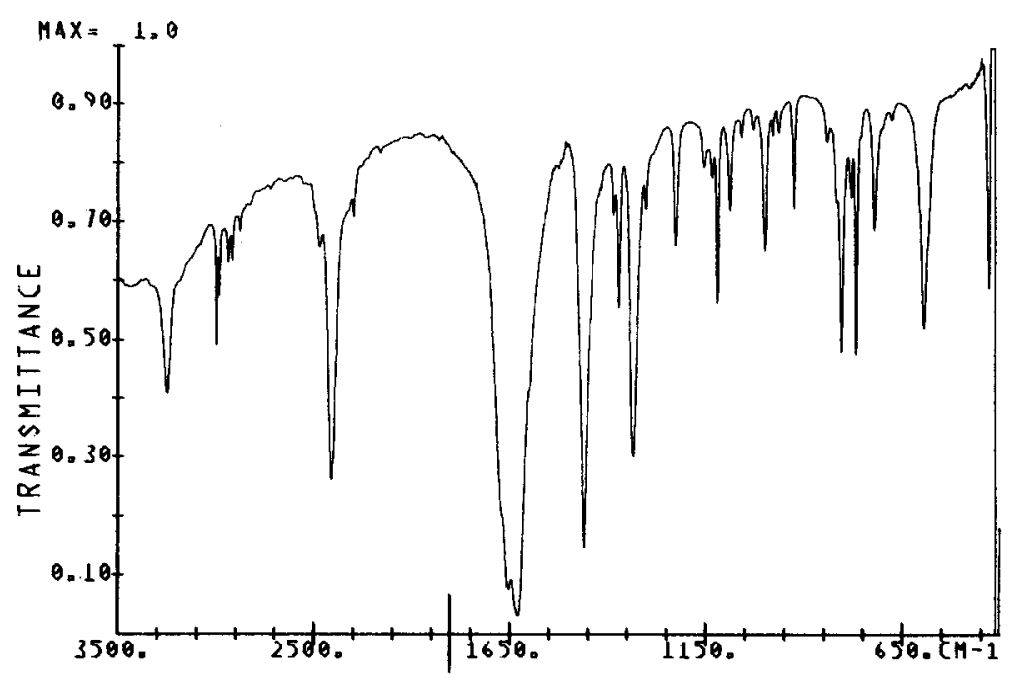

Fig. 11. I.r. spectrum of $N$-deuterated form I powder.

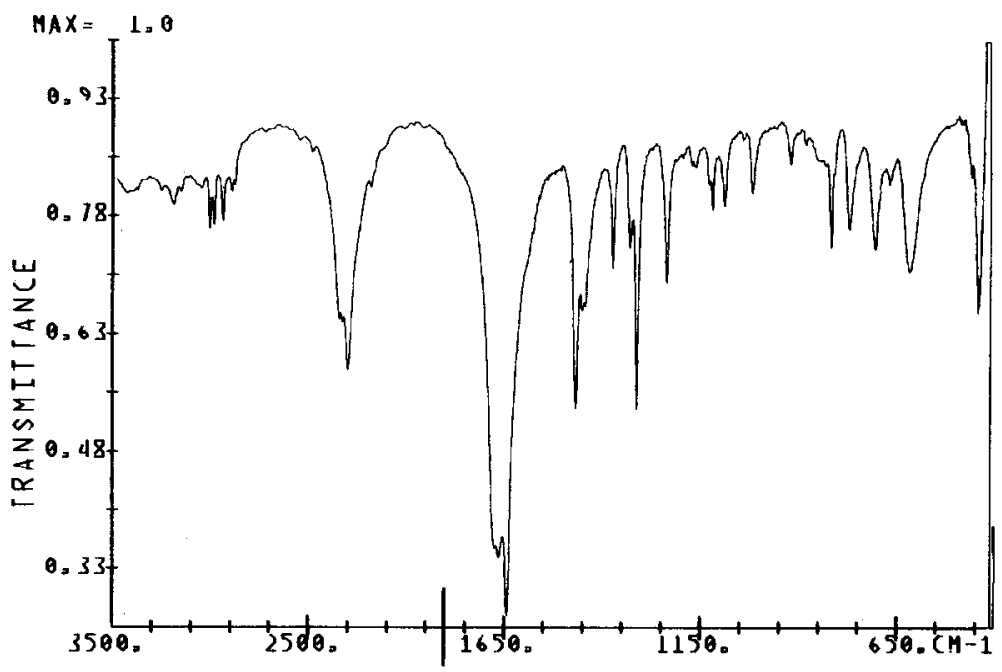

Fig. 12. I.r. spectrum of $N$-deuterated form II powder.

the main peak at $2411 \mathrm{~cm}^{-1}$ shifts to $2398 \mathrm{~cm}^{-1}$ at LT, while a shoulder at $2398 \mathrm{~cm}^{-1}$ becomes resolved at $2385 \mathrm{~cm}^{-1}$. In II the main sub-band at $2298 \mathrm{~cm}^{-1}$ is resolved at LT into two peaks at 2287 and $2279 \mathrm{~cm}^{-1}$, while the weaker sub-bands at 2344 and $2329 \mathrm{~cm}^{-1}$ move up to 2347 and $2331 \mathrm{~cm}^{-1}$. Thus, we again see a tendency, on cooling, for the main peak to shift down by about $10 \mathrm{~cm}^{-1}$ and for additional sub-bands to become resolved. The main Raman sub-bands are at $2402 \mathrm{~cm}^{-1}$ (I) and $2294 \mathrm{~cm}^{-1}$ (II), similar to the i.r. The single-crystal spectra of II-ND show the same sub-bands in both $A_{g}$ and $B_{g}$ polarizations. The positions of the dominant sub-band imply a shift in the ND str frequency of about $100 \mathrm{~cm}^{-1}$ from I to 11 . A value for the shift of the NH str mode is obviously more difficult to arrive at in view of the complexity in
II, but an estimate of $\sim \sqrt{ } 2 \times 100=140 \mathrm{~cm}^{-1}$ may be made, which would place the NH str frequency in II at about $3100 \mathrm{~cm}^{-1}$.

To summarize, the NH str band is characterized by much fine structure. The band in I, which is similar to the NH str in poly (L-alanine) and other polypeptides, is much narrower than in II, where the band resembles that in cyclo(Gly-Gly) even in the sub-band positions. Going to low temperature causes marked sharpening and downward shifts of about $10 \mathrm{~cm}^{-1}$, but some subbands shift up in frequency. An $A_{g}-B_{\theta}$ splitting of about $19 \mathrm{~cm}^{-1}$ is seen in $I$ but none is seen in II. There also seems to be no coincidence of the Raman and i.r. sub-band positions in either crystal form. From the narrower ND str bands, the frequency in I is found to be about $100 \mathrm{~cm}^{-1}$ higher than in II. These spectral 


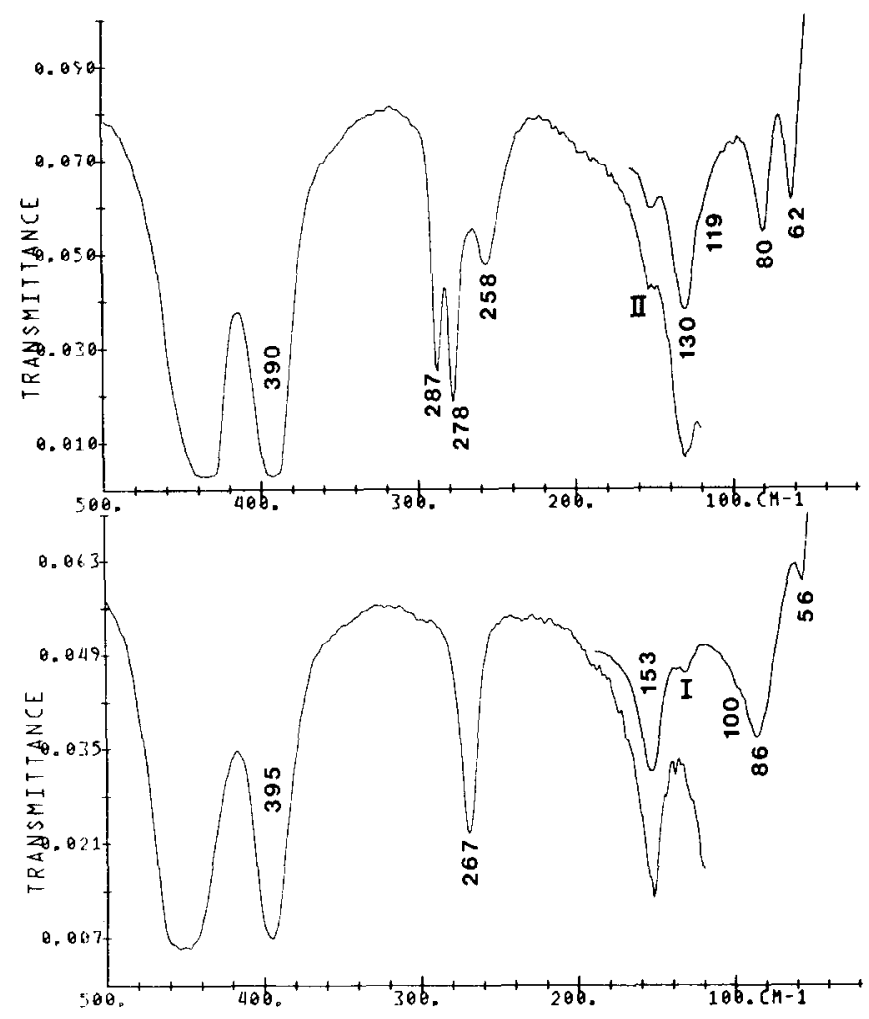

Fig. 13. Far-i.r. spectra of form I (top) and form II (bottom) powder.

differences are undoubtedly related to the different hydrogen bond patterns and strengths in the two forms.

In the $\mathrm{CH}$ str region five bands are found instead of the four expected. In I the Raman bands are at 2998, 2984, 2939, 2914, and $2877 \mathrm{~cm}^{-1}$. The 2939 and $2877 \mathrm{~cm}^{-1}$ peaks have the same polarization behaviour and are evidently involved in a Fermi resonance. By comparison with the well-characterized $\mathrm{CH}$ str region of L-alanine [13-15], we therefore assign the 2998 and $2984 \mathrm{~cm}^{-1}$ peaks to the $\mathrm{CH}_{3}$ antisymmetric stretches (as), the fundamental near $2939 \mathrm{~cm}^{-1}$ to $\mathrm{CH}_{3}$ symmetric stretch (ss), and the $2914 \mathrm{~cm}^{-1}$ band to $\mathrm{CH}^{\alpha}$ str. The corresponding frequencies in crystalline Lalanine are $3001,2987,2933$, and $2968 \mathrm{~cm}^{-1}$, respectively $[13,14]$; the $2933 \mathrm{~cm}^{-1}$ peak is also part of a Fermi doublet, the other component being at $2877 \mathrm{~cm}^{-1}$. The large difference in the $\mathrm{CH}^{\alpha}$ str frequency in L-alanine and I may be somewhat less surprising when it is noted that in II its position is even lower, at $2893 \mathrm{~cm}^{-1}$. Our assignment of this mode in cyclo(D-Ala-L-Ala) is supported by the single-crystal spectra: in $I$ it is strong in $y y$ polarization and weak in $x x$, whereas in II it is strong in $z z$ and weak in $y y$, and furthermore the i.r. band in $\mathbf{I I}$ has strong polarization along $z$; these observations are consistent with the direction of the $\mathrm{CH}^{\alpha}$ bond in the two forms. Another prominent difference between $I$ and $I I$ is that the $\mathrm{CH}_{3}$ as at $2998 \mathrm{~cm}^{-1}$ in $I$ moves up to $3011 \mathrm{~cm}^{-1}$ in II.
There are also some intensity changes: in both Raman and i.r. the $\mathrm{CH}^{\alpha}$ str is relatively stronger in $\mathrm{I}$, and the two $\mathrm{CH}_{3}$ as modes have more nearly equal Raman intensity in $\mathbf{I}$ but more nearly equal i.r. intensity in II (the i.r. $\mathrm{CH}$ stretches are best compared in the ND materials). In aqueous solution the $\mathrm{CH}^{\alpha}$ str and higher frequency $\mathrm{CH}_{3}$ as Raman bands become diffuse, with frequencies closer to those of form II. Because the other bands are also shifted, we cannot conclude from the $\mathrm{CH}$ str region that the form II conformation predominates in solution. As we will see, however, the $\mathrm{H}^{\alpha}$ bend modes do allow such a determination.

$1700-1200 \mathrm{~cm}^{-1}$ region. Eight modes are found in this region: three peptide group vibrations (CO str, $\mathrm{CN}$ str, and $\mathrm{NH}$ in-plane bend), three $\mathrm{CH}_{3}$ bends, and the two orthogonal $\mathrm{H}^{\alpha}$ bend modes.

The CO str, observed in the $1600 \mathrm{~cm}^{-1}$ region, shows an $\boldsymbol{A}-\boldsymbol{B}$ splitting in all spectra of the crystalline samples; in solution a singlet is seen. (An additional weak peak is seen near $1580 \mathrm{~cm}^{-1}$ in the Raman and i.r. spectra of I-NH. The Raman single-crystal spectra show this band to be in Fermi resonance with the $A_{g}$ $\mathrm{CO}$ str. Because of its weakness, we will neglect its effect.) The splittings $(A-B$ and $g-u)$, positions, and relative intensities are distinctly different in the various spectra. For instance, looking at the Raman spectra, we see in $I$ a larger $A_{g} B_{g}$ splitting $\left(48 \mathrm{~cm}^{-1}\right.$ versus $20 \mathrm{~cm}^{-1}$ ) and a higher relative intensity than in II, where the band is similar to that in cyclo(Gly-Gly). 

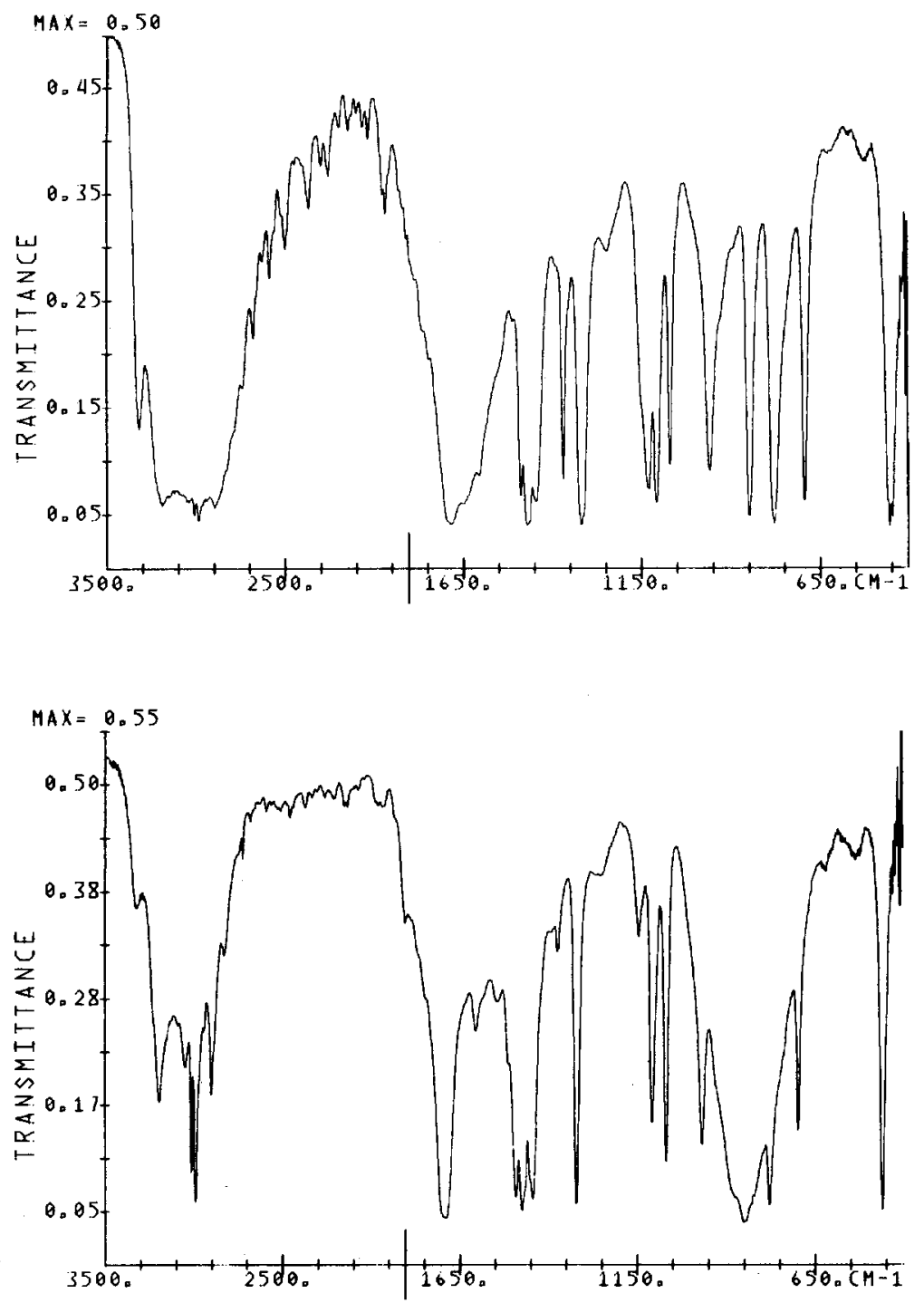

Fig. 14. I.r. spectra of form II single crystal, (100) section. Top: Electric vector parallel to $b$. Bottom: Electric vector parallel to $c$.

The single-crystal spectra show the $B\left(B_{q}\right.$ or $\left.B_{u}\right)$ component to be higher in frequency than the $A\left(A_{g}\right.$ or $A_{u}$ ). This result is conclusive for the Raman components and for the i.r. components of II, but is less so for the i.r. doublet of $I$ because of strong absorption. The large (factor of about 9) difference in integrated intensity of the i.r. components in I suggests that an $a b$ initio calculation of the transition moment direction would be useful. A calculation with the STO-3G basis of the dipole moment derivative for the $\mathrm{CO}$ str mode in cyclo(Gly-Gly) gives a transition moment oriented at about $16^{\circ}$ from the $\mathrm{CO}$ bond towards the $\mathrm{N} \rightarrow \mathrm{C}$ direction. This orientation would yield a ratio of the $A_{u}$ to $B_{u}$ intensities in $I$ of about 4 , which would confirm our assignment.

The $\mathrm{CN}$ str mode is readily assigned to strong bands near $1520 \mathrm{~cm}^{-1}$ (Raman) and near $1470 \mathrm{~cm}^{-1}$ (i.r.) in view of its nearly identical positions in cyclo(Gly-Gly). As we have noted [1], this mode can be described as mainly an out-of-phase $\mathrm{C}^{\alpha} \mathrm{CN}$ str (Fig. 15), with much less NH in-plane bend contribution than in the trans amide II mode; hence its relatively higher Raman intensity and smaller shift on $\mathrm{N}$-deuteration compared to the amide II. The band positions in I and II are nearly the same, indicating little sensitivity to the hydrogen bond structure, and the persistence of the large $g-u$ splitting in solution suggests an intramolecular rather than intermolecular origin.

$\mathrm{N}$-deuteration allows location of the $\mathrm{NH}$ in-plane bend (ib) at $1395 \mathrm{~cm}^{-1}$ (I) and $1428 \mathrm{~cm}^{-1}$ (II) in the Raman and at $1435 \mathrm{~cm}^{-1}$ (I) and $1488 \mathrm{~cm}^{-1}$ (II) in the i.r. The large shifts between I and II show a strong 
sensitivity to the hydrogen bond. The positions in II are close to those in cyclo(Gly-Gly), particularly in the $\mathrm{C}$-deuterated derivative of the latter, where the absence of coupling with $\mathrm{CH}_{2}$ bend in the Raman leaves the $\mathrm{NH}$ ib at $1437 \mathrm{~cm}^{-1}$. We note that the i.r. band in II is resolved from the $\mathrm{CN}$ str even at room temperature, unlike in cyclo(Gly-Gly), where its overlap with $\mathrm{CN}$ str hindered definitive assignment of the $\mathrm{NH}$ ib mode until our work [1]. Despite being near to the $\mathrm{CH}_{3}$ bend modes, there does not seem to be significant coupling: the Raman $\mathrm{CH}_{3}$ bends hardly shift on $\mathrm{N}$-deuteration. The ND ib does interact strongly with $\mathrm{NC}^{\alpha}$ str and $\mathrm{H}^{\alpha}$ bend, according to our calculations.

The two $\mathrm{CH}_{3}$ antisymmetric bends (ab), at around $1450 \mathrm{~cm}^{-1}$, are more clearly seen in the Raman spectra; the i.r. bands are not resolved from each other except in II-ND. In the Raman the higher frequency $\mathrm{CH}_{3}$ ab in II is stronger than the lower frequency $\mathrm{CH}_{3}$ ab but is nearly equally intense in $\mathbf{I}$, a trend that is also shown by the two $\mathrm{CH}_{3}$ as Raman modes.

Like the $\mathrm{CH}_{3}$ ab's, the $\mathrm{CH}_{3}$ symmetric bend (sb) has essentially the same frequency in $I$ as in $\mathbf{I}$, at about $1370 \mathrm{~cm}^{-1}$. It is weak and sharp in all spectra. The calculations show all three $\mathrm{CH}_{3}$ bend modes to be highly localized.

The assignment of the bands in the $1300-1340 \mathrm{~cm}^{-1}$ region to the two $\mathrm{H}^{\alpha}$ bend (b) modes is based on the normal mode calculations and on comparison with $\mathbf{L}$ alanine [13-15]. Figure 15 shows these modes to be relatively localized, with the higher frequency mode involving motion of the $\mathrm{H}^{\alpha}$ atom mainly in the $\mathrm{H}^{\alpha} \mathrm{C}^{\alpha} \mathrm{C}^{\beta}$ plane. The $\mathrm{H}^{\alpha}$ b modes show marked differences between I and II. Looking first at the Raman data, we see in I a very strong $1326 \mathrm{~cm}^{-1}$ band and a much weaker $1304 \mathrm{~cm}^{-1}$ peak, whereas in II the intensities are nearly equal and the separation of the two bands, at 1313 and $1300 \mathrm{~cm}^{-1}$, has decreased considerably. In the i.r. spectra a similar decrease of the separation, from $33 \mathrm{~cm}^{-1}$ to $9 \mathrm{~cm}^{-1}$, occurs but the higher frequency band remains much more intense than the other. On Ndeuteration, coupling of the i.r. $\mathrm{H}^{2} \mathrm{~b}$ vibrations with ND ib near $1230 \mathrm{~cm}^{-1}$ is indicated by the upward shifts in the $\mathrm{H}^{\alpha}$ b bands, which reduces the $\mathrm{H}^{\alpha} \mathbf{b}$ separation in I-ND to the point of overlap and increases it in II-ND. This interaction with ND ib is qualitatively reflected by the calculations; note, however, that no significant coupling with $\mathrm{NH}$ ib is indicated, in distinction to the trans amide, where such coupling is widespread. The Raman spectrum in $\mathrm{H}_{2} \mathrm{O}$ solution shows three peaks in the $\mathrm{H}^{\alpha} \mathrm{b}$ region. Thesc can be explained by the presence of both form I- and II-type molecules: the $1325 \mathrm{~cm}^{-1}$ peak is due to I, the $1311 \mathrm{~cm}^{-1}$ peak to II, and the $1300 \mathrm{~cm}^{-1}$ peak to both I and II. Molecules with form II conformation predominate, as shown by the relative intensities of the 1311 and $1325 \mathrm{~cm}^{-1}$ peaks. The i.r. solution spectrum may be similarly interpreted: the 1324, 1312, and $1294 \mathrm{~cm}^{-1}$ bands are attributed to I + II, II, and I, respectively. Similar statements may be made about the
$\mathrm{D}_{2} \mathrm{O}$ solution spectra. Thus, the differences in the $\mathrm{H}^{\alpha} \mathrm{b}$ frequencies in I and II occur in solution also and are therefore of intramolecular origin. In particular, they are not due to coupling with an NH ib vibration that occurs at different frequencies in $\mathbf{I}$ and II. Further indication of a structural dependence of the $\mathrm{H}^{x}$ b II-ND. In the Raman the higher frequency $\mathrm{CH}_{3} \mathrm{ab}$ in II is stronger than the lower frequency $\mathrm{CH}_{3}$ ab but is $1200-900 \mathrm{~cm}^{-1}$ region. Four modes occur in this region: $\mathrm{NC}^{\alpha}$ str, $\mathrm{C}^{\alpha} \mathrm{C}^{\beta}$ str, and two $\mathrm{CH}_{3}$ rock vibrations. Since four well-separated bands are observed, the assignment is straightforward, especially because the calculated frequencies agree well with those observed. The $\mathrm{NC}^{\alpha}$ str is seen from the calculations to be strongly mixed with $\mathrm{H}^{\alpha}$ b. N-deuteration shifts all four modes to lower frequencies, the magnitudes being smallest for the $\mathrm{C}^{\alpha} \mathrm{C}^{\beta}$ str $\left(\sim 20 \mathrm{~cm}^{-1}\right)$ and largest for the Raman $\mathrm{NC}^{\alpha} \operatorname{str}\left(\sim 100 \mathrm{~cm}^{-1}\right)$; the $\mathrm{CH}_{3}$ rock shifts range up to $60 \mathrm{~cm}^{-1}$. These shifts, which are quite well reproduced by the calculations, arise from new mixings involving ND ib. The main structure-sensitive feature in this region is the change in the Raman and i.r. intensities of the $\mathrm{CH}_{3}$ rock bands when the higher frequency mode moves up by about $10 \mathrm{~cm}^{-1}$ from I to II. The largest difference in frequency between $I$ and $I I$ in this region is the $20 \mathrm{~cm}^{-1}$ upward shift of the i.r. $\mathrm{CH}_{3}$ rock at $998 \mathrm{~cm}^{-1}$ in I-ND; as a result the two i.r. peaks at 1017 and $994 \mathrm{~cm}^{-1}$ in $\mathrm{D}_{2} \mathrm{O}$ solution can be attributed to types II and I molecules, respectively, further evidence that the molecules exist in solution in two discrete conformations.

$900-500 \mathrm{~cm}^{-1}$ region. From our cyclo(Gly-Gly) results, we expect in this region three peptide group vibrations- $\mathrm{NH}$ out-of-plane bend, $\mathrm{CO}$ out-of-plane bend, and the Raman-active CO in-plane bend-and a ring stretch mode and an i.r.-active ring deformation (def) mode, making a total of four bands in each spectrum. The observed bands are sufficiently similar to those in cyclo(Gly-Gly) to be readily assigned, except for the $\mathrm{CO}$ out-of-plane bend (ob).

In cyclo(Gly-Gly) the $\mathrm{CO}$ ob is a weak band around $560 \mathrm{~cm}^{-1}$ in both i.r. and Raman spectra. We assign this mode in I and II to bands near $690 \mathrm{~cm}^{-1}$ (i.r.) and $670 \mathrm{~cm}^{-1}$ (Raman), the much higher frequencies and intensities being due to coupling with ring and sidechain deformations. These couplings, which are negligible in the more nearly planar cyclo(Gly-Gly) structure, are confirmed by the calculations. (The poor frequency agreement, with the Raman $\mathrm{CO}$ ob lower than $\mathrm{CO} \mathrm{ib}$, contrary to our assignment, is no doubt due to the absence of force constants for these interactions.) Furthermore, on $\mathrm{N}$-deuteration the $\mathrm{CO}$ $o b$ bands shift up whereas the other bands in this region decrease in frequency, and the i.r. band in II-ND becomes more intense and shows stronger $z$ polarization. Similar changes were noted for cyclo(Gly-Gly) and are due to interaction of $\mathrm{CO}$ ob with ND ob. The small difference in frequency between I and II shows this mode to be not especially sensitive 


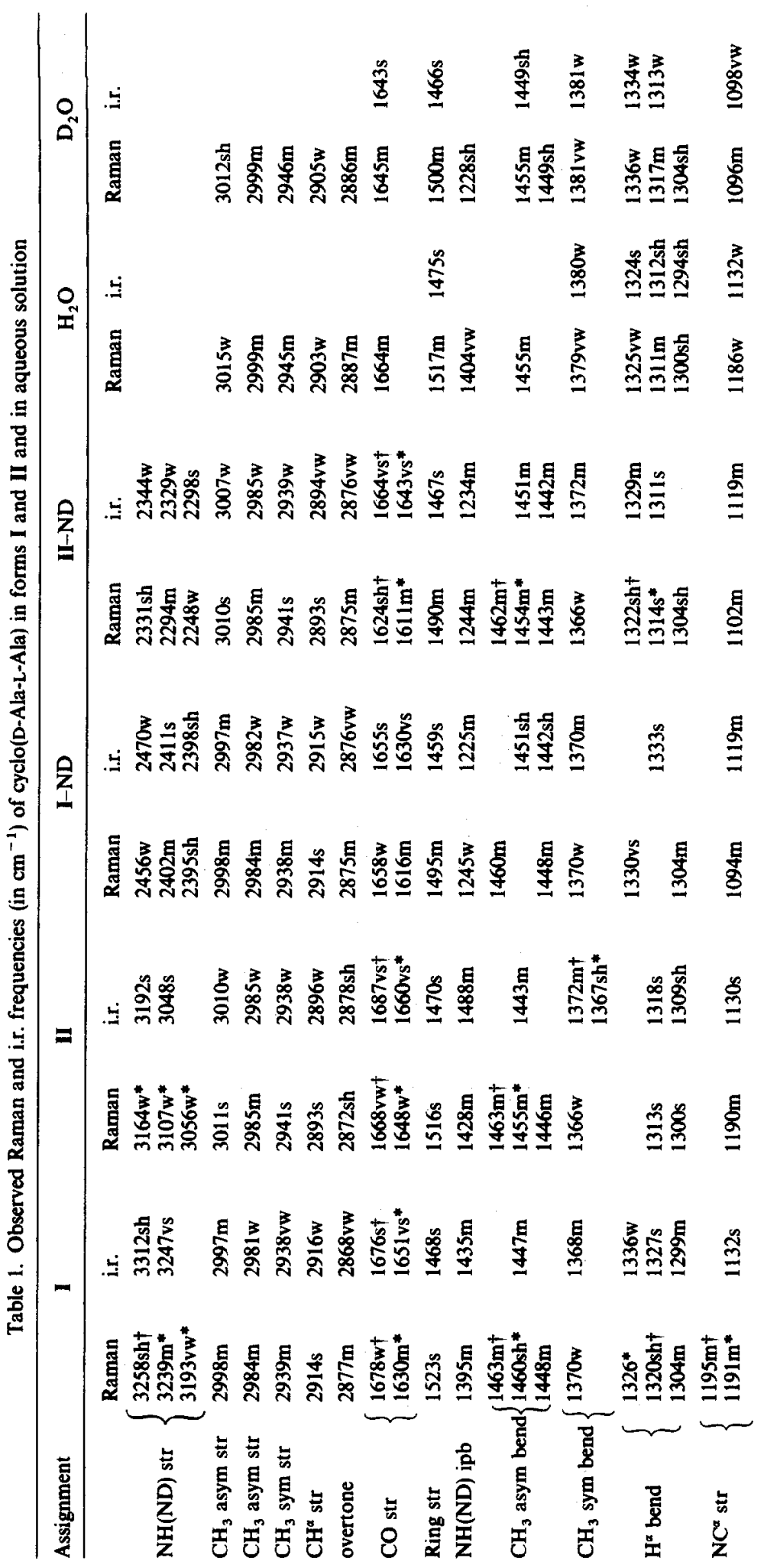




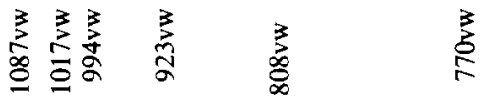

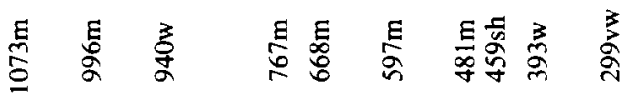

㿣

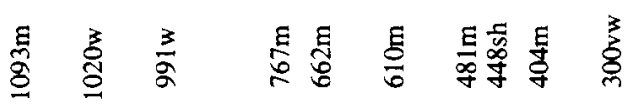

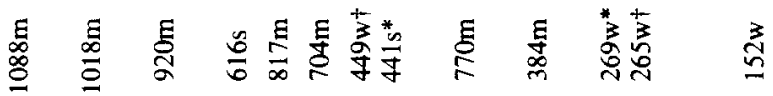

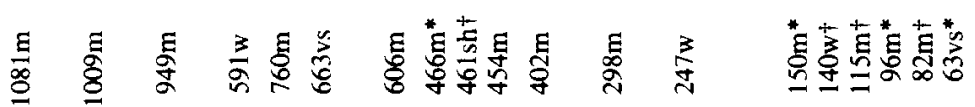

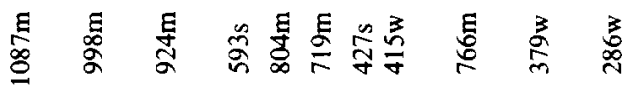

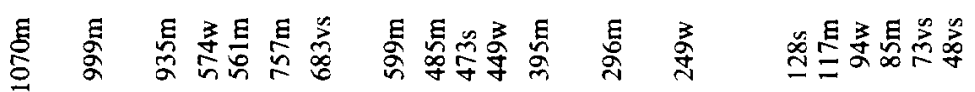

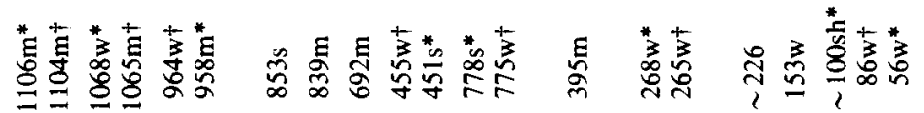

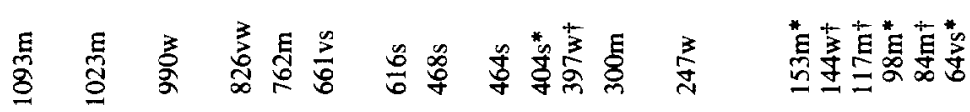

焉

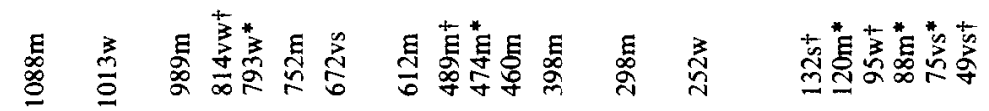

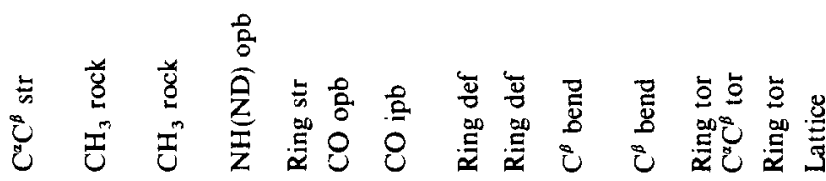


Table 2. Calculated intramolecular modes of II and II-ND, without intermolecular force constants

\begin{tabular}{|c|c|c|}
\hline $\begin{array}{c}\text { Obs.* } \\
\left(\mathrm{cm}^{-1}\right)\end{array}$ & $\begin{array}{l}\text { Calc. } \\
\left(\mathrm{cm}^{-1}\right)\end{array}$ & Potential energy distribution $(>10 \%) \dagger$ \\
\hline & & $\mathbf{I I}\left(A_{q}\right)$ \\
\hline$\sim 3100$ & 3074 & NH $\operatorname{str}(99)$ \\
\hline 3011 & 2994 & $\mathrm{CH}_{3}$ as $2(98)$ \\
\hline 2985 & 2989 & $\mathrm{CH}_{3}$ as $1(98)$ \\
\hline 2941 & 2916 & $\mathrm{CH}_{3} \mathrm{ss}(99)$ \\
\hline 2893 & 2903 & $\mathrm{CH}^{3} \operatorname{str}(98)$ \\
\hline 1658 & 1611 & $\mathrm{CO} \operatorname{str}(29), \mathrm{NH} i b(26), \mathrm{CN} \operatorname{str}(22), \mathrm{NC}^{\alpha} \operatorname{str}(15)$ \\
\hline 1516 & 1531 & $\mathrm{C}^{\alpha} \mathrm{C} \operatorname{str}(48), \mathrm{CO} \mathrm{ib}(18), \mathrm{CN} \operatorname{str}(16)$ \\
\hline 1459 & 1471 & $\mathrm{CH}_{3}$ ab1 (46), $\mathrm{CH}_{3}$ ab2(42) \\
\hline 1446 & 1461 & $\mathrm{CH}_{3}$ ab1 (44), $\mathrm{CH}_{3}$ ab2(43) \\
\hline 1428 & 1435 & NH ib(64), CO str(16) \\
\hline 1366 & 1369 & $\mathrm{CH}_{3} \mathrm{sb}(96)$ \\
\hline 1313 & 1315 & $H^{\alpha}$ b1 (42), $H^{\alpha}$ b2(15), $N C^{\alpha} \operatorname{str}(13)$ \\
\hline 1300 & 1275 & $\mathrm{H}^{\alpha}$ b2(40), $\mathrm{H}^{\alpha}$ b1 $(23), \mathrm{CO} \operatorname{str}(14)$ \\
\hline 1190 & 1173 & $H^{\alpha}$ b2(38), $N C^{\alpha} \operatorname{str}(19), C O \operatorname{str}(13)$ \\
\hline 1093 & 1071 & $\mathrm{C}^{a} \mathrm{C}^{\beta} \operatorname{str}(57), \mathrm{CH}_{3} \mathrm{rl}(28)$ \\
\hline 1023 & 1016 & $\mathrm{CH}_{3} \mathrm{r} 2(31), \mathrm{CH}_{3} \mathrm{rl}(21), \mathrm{H}^{\alpha}$ bl(14) \\
\hline 990 & 983 & $\mathrm{CH}_{3} \mathrm{r} 2(31), \mathrm{C}^{\alpha} \mathrm{C}^{\beta} \operatorname{str}(13), \mathrm{CH}_{3} \mathrm{rl}(13)$ \\
\hline 826 & 825 & NH ob(54) \\
\hline 762 & 741 & $\mathrm{NC}^{\alpha} \mathrm{Cdef}(17), \mathrm{CH}_{3} \mathrm{rl}(16), \mathrm{C}^{\alpha} \mathrm{C} \operatorname{str}(14), \mathrm{CO}$ ob(14) \\
\hline 616 & 639 & $\mathrm{CO} i b(48), C^{\beta} \mathrm{b} 2(20), C N \operatorname{str}(16)$ \\
\hline 661 & 612 & $\mathrm{CO}$ ob(32), $\mathrm{C}^{\alpha} \mathrm{C} \operatorname{str}(18)$ \\
\hline 471 & 479 & $\mathrm{CNC}^{\alpha} \operatorname{def}(25), \mathrm{C}^{\beta}$ bl(18) \\
\hline 464 & 424 & $C^{\alpha} C N \operatorname{def}(27), N C^{\alpha} \operatorname{str}(21), C^{\beta} b l(19), N C^{\alpha} C \operatorname{def}(11)$ \\
\hline 401 & 362 & $C^{\beta}$ b2(35), $N C^{\alpha} C \operatorname{def}(15)$ \\
\hline 300 & 297 & $C^{\beta}$ b2(34), NC $C^{\alpha} C \operatorname{def}(18), C O$ ob(14), $C^{\beta}$ bl(13) \\
\hline - & 242 & $C^{x} C^{\beta} \operatorname{tor}(96)$ \\
\hline \multirow[t]{2}{*}{247} & 149 & $\mathrm{C}^{2} \mathrm{C}$ tor(53), $\mathrm{N} C^{\alpha} \operatorname{tor}(37), \mathrm{CN}$ tor( $(32)$ \\
\hline & & II $\left(A_{u}\right)$ \\
\hline$\sim 3100$ & 3078 & NH $\operatorname{str}(99)$ \\
\hline 3010 & 2994 & $\mathrm{CH}_{3}$ as $2(98)$ \\
\hline 2985 & 2989 & $\mathrm{CH}_{3}$ as $1(98)$ \\
\hline 2938 & 2916 & $\mathrm{CH}_{3} \mathrm{ss}(99)$ \\
\hline 2896 & 2903 & $\mathrm{CH}^{\alpha} \operatorname{str}(98)$ \\
\hline 1674 & 1671 & $\mathrm{CO} \operatorname{str}(57), \mathrm{NH} i b(21), \mathrm{C}^{\alpha} \mathrm{CN} \operatorname{def}(14)$ \\
\hline 1488 & 1514 & NH ib(56), CO $\operatorname{str}(16)$ \\
\hline 1443 & 1470 & $\mathrm{CH}_{3} \mathrm{ab} 2(63), \mathrm{CH}_{3} \mathrm{abl}(25)$ \\
\hline 1443 & 1468 & $\mathrm{CH}_{3}$ abl(57), $\mathrm{CH}_{3}$ ab2(23) \\
\hline 1470 & 1428 & $\mathrm{C}^{\alpha} \mathrm{C} \operatorname{str}(21), C N \operatorname{str}(18), \mathrm{CO}$ ib(17) \\
\hline 1370 & 1369 & $\mathrm{CH}_{3} \mathrm{sb}(98)$ \\
\hline 1318 & 1311 & $\mathrm{H}^{\alpha} \mathrm{b} 1(52)$ \\
\hline 1309 & 1300 & $\mathrm{H}^{\alpha}$ b2(59) \\
\hline 1130 & 1155 & $\mathrm{H}^{\alpha} \mathrm{b} 2(33), \mathrm{CH}_{3} \mathrm{r} 2(19), \mathrm{NC}^{\alpha} \operatorname{str}(11)$ \\
\hline 1106 & 1111 & $\mathrm{C}^{\alpha} \mathrm{C}^{\beta} \operatorname{str}(52)$ \\
\hline 1066 & 1047 & $\mathrm{CH}_{3}$ rl(45), $\mathrm{H}^{\alpha}$ bl(23), $\mathrm{NC}^{\alpha} \mathrm{C} \operatorname{def}(11)$ \\
\hline 451 & 962 & $\mathrm{CH}_{3} \mathrm{r} 2(41), \mathrm{NC}^{\alpha} \operatorname{str}(16), \mathrm{CNC} \mathrm{C}^{\alpha} \operatorname{def}(12)$ \\
\hline 839 & 854 & $\mathrm{CH}_{3}$ rl(21), $\mathrm{C}^{\alpha} \mathrm{C}^{\beta} \operatorname{str}(19)$ \\
\hline 853 & 829 & $\mathrm{NH} \mathrm{ob}(44), \mathrm{CH}_{3} \mathrm{r} 2(11)$ \\
\hline 778 & 775 & NH ob(31), $C^{\alpha} C^{\beta} \operatorname{str}(16), C^{\alpha} C N \operatorname{def}(14)$ \\
\hline 692 & 626 & $\mathrm{CO} o b(63), N C^{\alpha} \mathrm{C} \operatorname{def}(12)$ \\
\hline 453 & 433 & $\mathrm{NC}^{\alpha} \mathrm{C} \operatorname{def}(35), \mathrm{CO} \mathrm{ib}(19), \mathrm{CO}$ ob(12) \\
\hline 395 & 358 & $\mathrm{CO} \mathrm{ib(47)}$ \\
\hline 267 & 272 & $\mathrm{C}^{\beta} \mathrm{b} 2(62), \mathrm{CO}$ ob(17) \\
\hline$\sim 226$ & 239 & $\mathrm{C}^{\alpha} \mathrm{C}^{\beta}$ tor $(96)$ \\
\hline$\sim 260$ & 149 & CN tor(39), NH ob(15) \\
\hline \multirow[t]{2}{*}{153} & 82 & $\mathrm{C}^{\alpha} \mathrm{C}$ tor $(48), \mathrm{NC}^{\alpha}$ tor(34) \\
\hline & & II-ND $\left(A_{\theta}\right)$ \\
\hline 3010 & 2994 & $\mathrm{CH}_{3}$ as2(98) \\
\hline 2985 & 2989 & $\mathrm{CH}_{3}$ asl(98) \\
\hline 2941 & 2916 & $\mathrm{CH}_{3} \mathrm{ss}(99)$ \\
\hline 2893 & 2903 & $\mathrm{CH}^{\mathrm{a}} \operatorname{str}(98)$ \\
\hline$\sim 2300$ & 2262 & ND $\operatorname{str}(97)$ \\
\hline 1618 & 1590 & CO str(37), CN str(24), NC $C^{\alpha} \operatorname{str}(16)$ \\
\hline 1490 & 1525 & $\mathrm{C}^{a} \mathrm{C} \operatorname{str}(47), \mathrm{CO} \mathrm{ib}(18), \mathrm{CN} \operatorname{str}(16)$ \\
\hline 1458 & 1470 & $\mathrm{CH}_{3} \mathrm{abl}(51), \mathrm{CH}_{3} \mathrm{ab} 2(38)$ \\
\hline 1443 & 1460 & $\mathrm{CH}_{3}$ ab2(51), $\mathrm{CH}_{3}$ ab1(38) \\
\hline
\end{tabular}


Table 2 (Contd.)

\begin{tabular}{|c|c|c|}
\hline 1366 & 1369 & $\mathrm{CH}_{3} \mathrm{sb}(96)$ \\
\hline 1318 & 1313 & $\mathrm{H}^{\alpha}$ b1 (42), $\mathrm{H}^{\alpha}$ b2(14), $\mathrm{NC}^{\alpha} \operatorname{str}(13)$ \\
\hline 1304 & 1276 & $\mathrm{H}^{\alpha}$ b2 (49), $\mathrm{H}^{\alpha}$ b1(20) \\
\hline 1244 & 1224 & $\mathrm{CO} \operatorname{str}(24), \mathrm{ND} \mathrm{ib}(22), \mathrm{H}^{x}$ b2 $(20), \mathrm{NC}^{x} \operatorname{str}(18)$ \\
\hline 1102 & 1094 & $\mathrm{ND}$ ib(34), $\mathrm{CH}_{3} \mathrm{r} 2(32), \mathrm{H}^{2} \mathrm{~b} 2(15)$ \\
\hline 1081 & 1070 & $\mathrm{C}^{\alpha} \mathrm{C}^{\beta} \operatorname{str}(57), \mathrm{CH}_{3}$ rl(30) \\
\hline 1009 & 1002 & $\mathrm{CH}_{3}$ rl(33), $\mathrm{H}^{\alpha}$ bl $(22), \mathrm{C}^{\alpha} \mathrm{C}^{\beta} \operatorname{str}(19)$ \\
\hline 949 & 939 & $\mathrm{CH}_{3} \mathrm{r} 2(38), \mathrm{ND} \mathrm{ib}(28), \mathrm{NC}^{\alpha} \operatorname{str}(12)$ \\
\hline 760 & 745 & $\begin{array}{l}\mathrm{NC}^{a} \mathrm{C} \operatorname{def}(21), \mathrm{CH}_{3} \text { r1(18), } \mathrm{CO} \text { ob(14), ND ob(12), } \mathrm{C}^{x} \mathrm{C} \\
\text { str(11) }\end{array}$ \\
\hline 591 & 651 & ND ob(35), $C^{\beta}$ b2(11) \\
\hline 663 & 612 & $\mathrm{CO}$ ob(19), CN str(16), $\mathrm{CO}$ ib(12), ND ob(12) \\
\hline 606 & 599 & $\mathrm{CO}$ ib(33), $\mathrm{CO}$ ob(16), $\mathrm{C}^{\circ} \mathrm{C} \operatorname{str}(14)$ \\
\hline 464 & 472 & $\mathrm{CNC}^{2} \operatorname{def}(26), \mathrm{C}^{\beta} \mathrm{b} 1(18)$ \\
\hline 454 & 424 & $C^{\alpha} C N$ def(27), $N C^{\alpha} \operatorname{str}(21), C^{\beta}$ bl(20). $N C^{\alpha} C \operatorname{def}(11)$ \\
\hline 402 & 349 & $\mathrm{C}^{\beta} \mathrm{b} 2(34), N C^{\alpha} \mathrm{C} \operatorname{def}(17)$ \\
\hline 298 & 297 & $C^{\beta}$ b2 (35), NC $C^{\alpha} C \operatorname{def}(17), C O$ ob (14), $C^{\beta}$ b1(13) \\
\hline - & 242 & $C^{\alpha} C^{\beta}$ tor $(96)$ \\
\hline \multirow[t]{2}{*}{247} & 143 & $\mathrm{C}^{\alpha} \mathrm{C}$ tor(53), $\mathrm{NC}^{\alpha}$ tur(39), $\mathrm{CN}$ tor(35). \\
\hline & & II-ND $\left(A_{u}\right)$ \\
\hline 3007 & 2994 & $\mathrm{CH}_{3}$ as $2(98)$ \\
\hline 2985 & 2989 & $\mathrm{CH}_{3}$ as $1(98)$ \\
\hline 2939 & 2916 & $\mathrm{CH}_{3} \mathrm{ss}(99)$ \\
\hline 2894 & 2903 & $\mathrm{CH}^{z} \sin (98)$ \\
\hline$\sim 2300$ & 2272 & ND $\operatorname{str}(96)$ \\
\hline 1654 & 1647 & $\mathrm{CO} \operatorname{str}(72), \mathrm{C}^{x} \mathrm{CN} \operatorname{def}(17)$ \\
\hline 1451 & 1472 & $\mathrm{CH}_{3}$ abl(76) \\
\hline 1442 & 1469 & $\mathrm{CH}_{3}$ ab2(76) \\
\hline 1467 & 1424 & $C^{a} \mathrm{C} \operatorname{str}(23), C O \mathrm{ib}(16), C N \operatorname{str}(15)$ \\
\hline 1329 & 1370 & $\mathrm{CH}_{3} \operatorname{sb}(37), \mathrm{H}^{\alpha}$ bl (23), $\mathrm{C}^{\alpha} \mathrm{C}^{\beta} \operatorname{str}(12)$ \\
\hline 1372 & 1367 & $\mathrm{CH}_{3} \mathrm{sb}(63)$ \\
\hline 1311 & 1301 & $\mathrm{H}^{\alpha} \mathrm{b} 2(64)$ \\
\hline 1234 & 1231 & $\mathrm{H}^{2}$ bl(35), ND ib(26) \\
\hline 1119 & 1146 & $\mathrm{H}^{2} \mathrm{~b} 2(32), \mathrm{CH}_{3}+2(22)$ \\
\hline 1088 & 1079 & $\mathrm{C}^{x} \mathrm{C}^{\beta} \operatorname{str}(48), \mathrm{CH}_{3} \mathrm{rl}(26)$ \\
\hline 1018 & 1009 & $\mathrm{CH}_{3} \mathrm{rl}(34), \mathrm{H}^{2}$ bl(22), ND ib(14) \\
\hline 920 & 932 & $\mathrm{CH}_{3} \mathrm{r} 2(47), \mathrm{NC}^{\alpha} \operatorname{str}(15)$ \\
\hline 817 & 808 & $C^{\alpha} C^{\beta} \operatorname{str}(23), \mathrm{CH}_{3} r 1(16), \mathrm{NC}^{\alpha} \mathrm{C} \operatorname{def}(13)$ \\
\hline 770 & 777 & ND $i b(21), C^{x} C N \operatorname{def}(14)$ \\
\hline 616 & 669 & $\mathrm{ND} o b(76), \mathrm{CO} \circ b(24)$ \\
\hline 704 & 618 & $\mathrm{CO}$ ob(44), $\mathrm{NC}^{x} \mathrm{C} \operatorname{def}(16)$ \\
\hline 445 & 399 & $\mathrm{CO} \mathrm{ib}(37), \mathrm{NC}^{\circ} \mathrm{C} \operatorname{def}(20)$ \\
\hline 384 & 347 & $\mathrm{CO}$ ih(29), $\mathrm{N} C^{\alpha} \mathrm{C} \operatorname{def}(14), \mathrm{C}^{\beta}$ b2(12) \\
\hline 267 & 271 & $\mathrm{C}^{\beta} \mathrm{b} 2(60), \mathrm{CO}$ ob $(18)$ \\
\hline - & 239 & $C^{\alpha} C^{\beta} \operatorname{tor}(96)$ \\
\hline- & 145 & $C N$ tor(41), ND ob(13) \\
\hline - & 82 & $\mathrm{C}^{\alpha} \mathrm{C}$ tor $(48), N C^{\alpha}$ tor $(35)$ \\
\hline
\end{tabular}

*From crystalline samples. Where A-B splittings are observed, average frequency is listed.

+ Abbreviations: $\mathrm{str}=$ stretch, as = antisymmetric str, ss = symmetric str, $\mathrm{b}$ $=$ bend, $a b=$ antisymmetric $b, s b=$ symmetric $b$, def $=$ deformation, $i b=i n-$ plane $b, o b=$ out-of-plane $b, r=$ rock, tor $=$ torsion.

to the hydrogen bond structure, perhaps because of its highly mixed character.

The NH ob mode, easily identified by $\mathrm{N}$ deuteration, appears in II at nearly the same positions as in cyclo(Gly-Gly), $853 \mathrm{~cm}^{-1}$ (i.r.) and $826 \mathrm{~cm}^{-1}$ (Raman). In I this mode is at $808 \mathrm{~cm}^{-1}$ (i.r.) and $804 \mathrm{~cm}^{-1}$ (Raman); thus, the fractional shift of this mode from I to II is comparable to that of the NH str. The Raman ND ob mode is much more intense than the $\mathrm{NH}$ ob because of coupling with $\mathrm{CO}$ ob, as we saw also in cyclo(Gly-Gly).
The remaining two i.r. bands in this region, near 839 and $780 \mathrm{~cm}^{-1}$, are easily assigned to the ring str and def vibrations. The calculations show these modes to be highly mixed. The $\mathrm{C}^{\alpha} \mathrm{C}$ (or ring) str mode in the Raman is near $760 \mathrm{~cm}^{-1}$, its much weaker intensity compared to that in cyclo(Gly-Gly) being due to coupling with $\mathrm{CO}$ ob and other coordinates. Finally, the Raman $\mathrm{CO}$ ib is placed at $612 \mathrm{~cm}^{-1}$ in $\mathbf{I}$ and at $616 \mathrm{~cm}^{-1}$ in II, essentially the same position as in cyclo(Gly-Gly).

Intramolecular modes below $500 \mathrm{~cm}^{-1}$. Six internal modes are expected in each spectrum below $500 \mathrm{~cm}^{-1}$ : 
Table 3. Calculated lattice modes of $I$ and II, in $\mathrm{cm}^{-1}$

\begin{tabular}{lrrrr}
\hline & \multicolumn{2}{c}{ I } & \multicolumn{2}{c}{ Il } \\
Symmetry & Calc. & Obs. & Calc. & Obs. \\
\hline \multirow{2}{*}{$A_{\boldsymbol{q}}$} & 136 & 120 & 147 & 153 \\
& 95 & 88 & 114 & 98 \\
& 73 & 75 & 75 & 64 \\
$B_{\boldsymbol{g}}$ & 132 & 132 & 146 & 144 \\
& 111 & 95 & 114 & 117 \\
& 52 & 49 & 85 & 84 \\
$A_{u}$ & 142 & 119 & 123 & 100 \\
& 77 & 62 & 72 & 56 \\
$B_{u}$ & 80 & 80 & 80 & 86 \\
\hline
\end{tabular}

two $C^{\beta}$ bends and $C^{\alpha} C^{\beta}$ torsion; in addition, two ring deformations and one ring torsion in the Raman, and $\mathrm{CO}$ in-plane bend and two ring torsions in the i.r. The Raman modes are well separated from the lattice modes and are easily assigned, except for the $\mathrm{C}^{\alpha} \mathrm{C}^{\beta}$ torsion (tor) which is not observed. In the i.r. the location of one of the ring tor modes among the lattice modes makes our assignment of this ring tor vibration as well as of the translatory lattice modes tentative at present.

The Raman-active ring def modes are seen at nearly the same frequencies as in cyclo(Gly-Gly), around $470 \mathrm{~cm}^{-1}$, and also with an observable splitting of the higher frequency mode.

The i.r. band in the $400 \mathrm{~cm}^{-1}$ region is clearly the $\mathrm{CO} \mathrm{ib}$ mode in view of its similar position in cyclo(GlyGly). Its frequency in $I I$ is $20 \mathrm{~cm}^{-1}$ higher than in $I$, a fractional shift of $4.6 \%$. Thus, the i.r.-active $\mathrm{CO}$ ib seems much more sensitive to the hydrogen bond structure than does its Raman counterpart.

The two measured $C^{\beta}$ b frequencies near 400 and $300 \mathrm{~cm}^{-1}$ agree well with the calculated values. The lower frequency $\mathrm{C}^{\beta}$ b shows an i.r. splitting that is clearly seen in the powder spectrum of I, but which in II requires polarized spectra to be resolved. The $C^{\beta} b$ modes are distinguished from the other low frequency i.r. and Raman bands by their insensitivity to cooling.

The remaining internal modes in this region are the torsions. The weak, broad Raman band near $250 \mathrm{~cm}^{-1}$ corresponds to the ring tor in cyclo(Gly-Gly). The $\mathrm{C}^{2} \mathrm{C}^{\beta}$ tor is also expected in the $200 \mathrm{~cm}^{-1}$ region, but no other peak is observed. The data on L-alanine are not a useful guide here because of disagreements in the assignments $[14,15]$. In the i.r. this mode is expected to be very weak, and we tentatively assign it to a weak band at $226 \mathrm{~cm}^{-1}$ that is seen only in the lowtemperature spectra of I and II. The Raman mode may very likely be overlapped with the ring tor at $250 \mathrm{~cm}^{-1}$. Thus, except for the $C^{\alpha} C^{\beta}$ tor, all Raman-active internal modes are satisfactorily assigned.

One of the i.r. ring tor modes is also expected in the $200-300 \mathrm{~cm}^{-1}$ range and is assigned to the broad $258 \mathrm{~cm}^{-1}$ band in I, which sharpens considerably and shifts up by $5 \mathrm{~cm}^{-1}$ on cooling. In II no corresponding peak is apparent. It is possible that the $10 \mathrm{~cm}^{-1}$ downward shift of the $\mathrm{C}^{\beta} \mathrm{b}$ mode in II has resulted in an overlap with the ring tor. The reason for the appreciable i.r. intensity of the ring tor mode, at least in I, compared to that in cyclo(Gly-Gly) is not obvious and may be checked by an $a b$ initio calculation; we recall that in the latter compound we placed this mode at $285 \mathrm{~cm}^{-1}$ on the basis of neutron scattering data [18] because no i.r. peak was seen. The lower frequency i.r. ring tor may be mixed with the lattice vibrations. We will therefore merely mention that we assign it to bands at $130 \mathrm{~cm}^{-1}$ (I) and $153 \mathrm{~cm}^{-1}$ (II), and defer further discussion until we consider the translatory lattice modes.

Lattice modes. The six rotatory lattice vibrations are readily classified into $A_{\theta}$ or $B_{\theta}$ species using the singlecrystal spectra. They are very different in frequency and relative intensity in I and II, and also in cyclo(Gly-Gly), as would be expected. They all sharpen at low temperature and shift by up to $3 \mathrm{~cm}^{-1}$ in $I$ and up to $7 \mathrm{~cm}^{-1}$ in II.

The i.r. translatory lattice modes are not as conclusively assigned. Because one of the ring tor modes falls in the same region, we expect to find four bands. The $130 \mathrm{~cm}^{-1}$ band in I shows significant intensity in the single-crystal spectra both parallel and perpendicular to $y$ and is therefore most likely an internal mode. The $153 \mathrm{~cm}^{-1}$ peak in II is then assigned as the corresponding ring tor in the other crystal form; the large shift may be caused by coupling with lattice vibrations, an interaction that is indicated by our calculations. Of the remaining bands, the $80 \mathrm{~cm}^{-1}$ (I) and $86 \mathrm{~cm}^{-1}$ (II) peaks show clear perpendicular dichroism and can be assigned to the $B_{u}$ lattice mode. The $62 \mathrm{~cm}^{-1}$ (I) and $56 \mathrm{~cm}^{-1}$ (II) peaks are apparently polarized parallel to $y$ and are accordingly one of the $A_{u}$ lattice vibrations. Weak bands seen near $119 \mathrm{~cm}^{-1}$ in $I$ and $100 \mathrm{~cm}^{-1}$ in II are then the other $A_{u}$ lattice mode. What makes our assignment of the $A_{u}$ modes quite tentative at present is that the polarizations of the 119,100 and $56 \mathrm{~cm}^{-1}$ peaks are not definitive because of their weakness. Also, at low temperature the $62 \mathrm{~cm}^{-1}$ peak in the powder spectrum of $I$ is a doublet; whether the other band is due to a form II impurity is not yet certain.

Our calculated lattice-mode frequencies (Table 3) using MOMANY et al.'s [12] atom-atom potential agree well with the $A_{g}$ and $B_{g}$ observed values, as was found also for cyclo(Gly-Gly). The relatively, wellassigned $B_{u}$ lattice mode is also well reproduced, and the poorer agreement of the higher frequency $A_{u}$ mode may be because of coupling with the ring torsions. The good performance of this potential further supports our conclusion [2] that this set of parameters is very satisfactory for peptide crystals. We also note that, using the crystal-packing program MCA [19], we have minimized the energy of forms I and II using these potential parameters by allowing rigid body rotations and translations. We find that form I is slightly more stable than II, with crystal energy of $-9.924 \mathrm{kcal} / \mathrm{mole}$ versus $-9.452 \mathrm{kcal} / \mathrm{mole}$. 


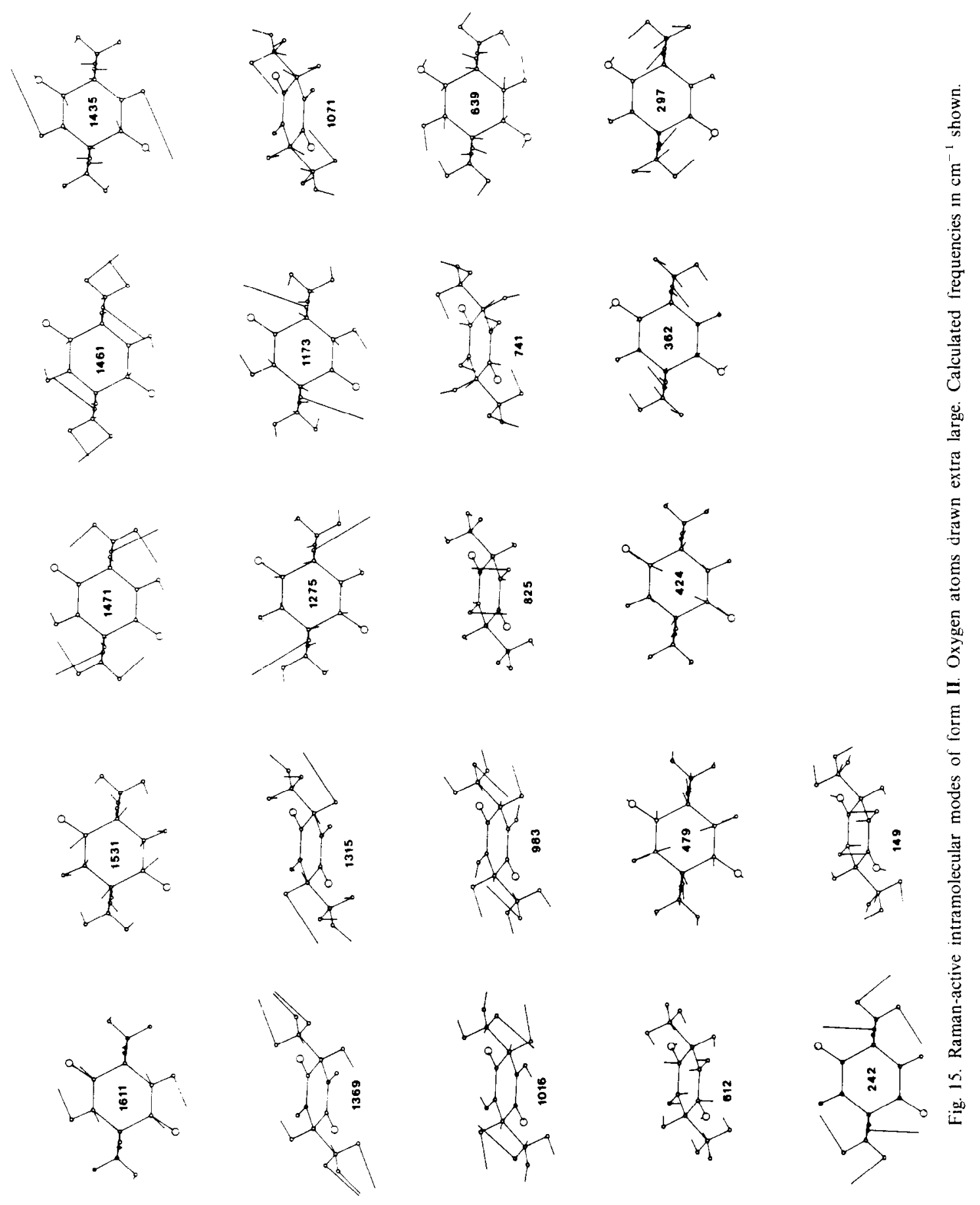



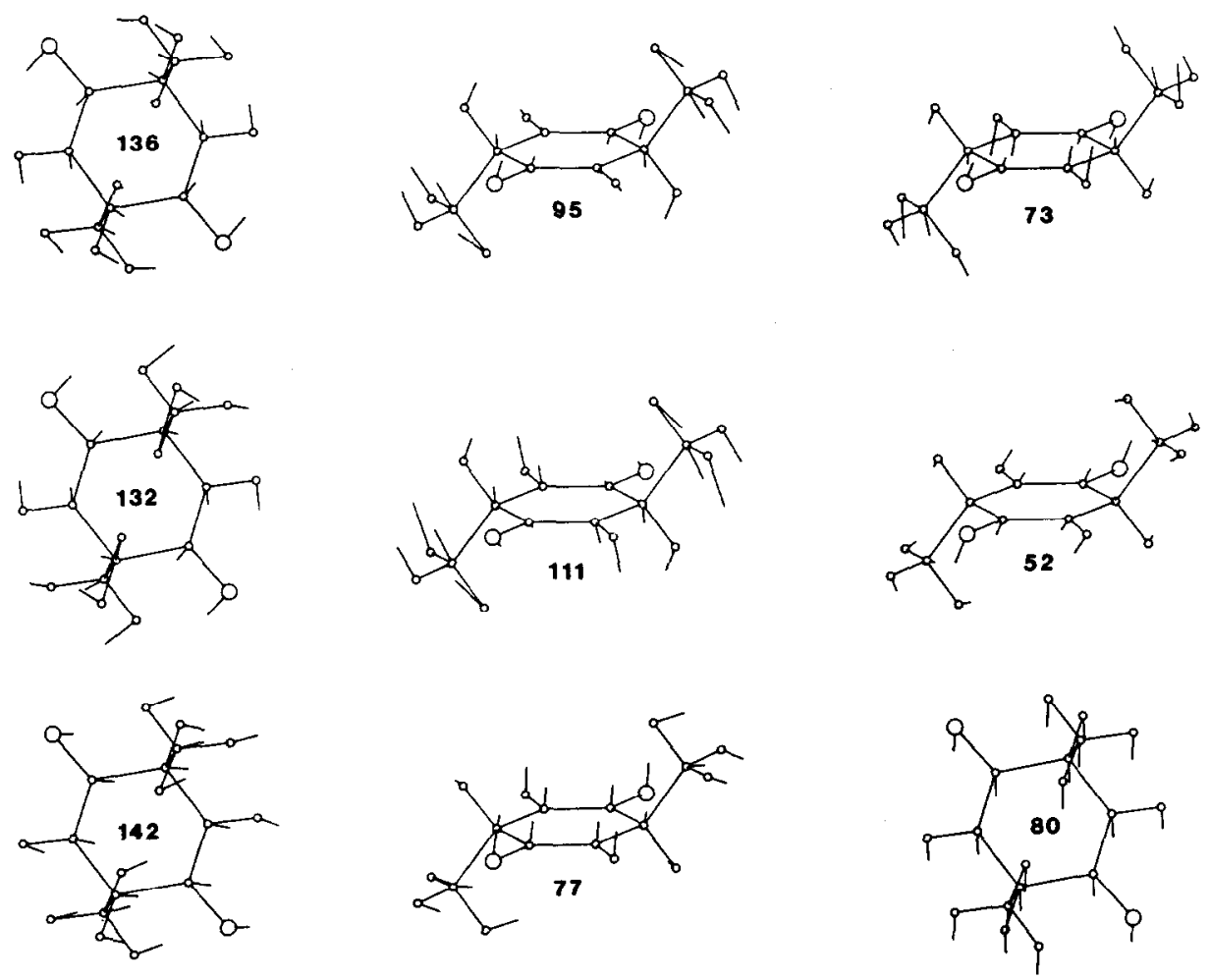

Fig. 16. Lattice modes of form $I$. Oxygen atoms drawn extra large. Top row: $\boldsymbol{A}_{\boldsymbol{q}}$. Middle row: $\boldsymbol{B}_{\boldsymbol{g}}$. Bottom row: $A_{u}$ and $B_{w}$. Calculated frequencies in $\mathrm{cm}^{-1}$ shown.
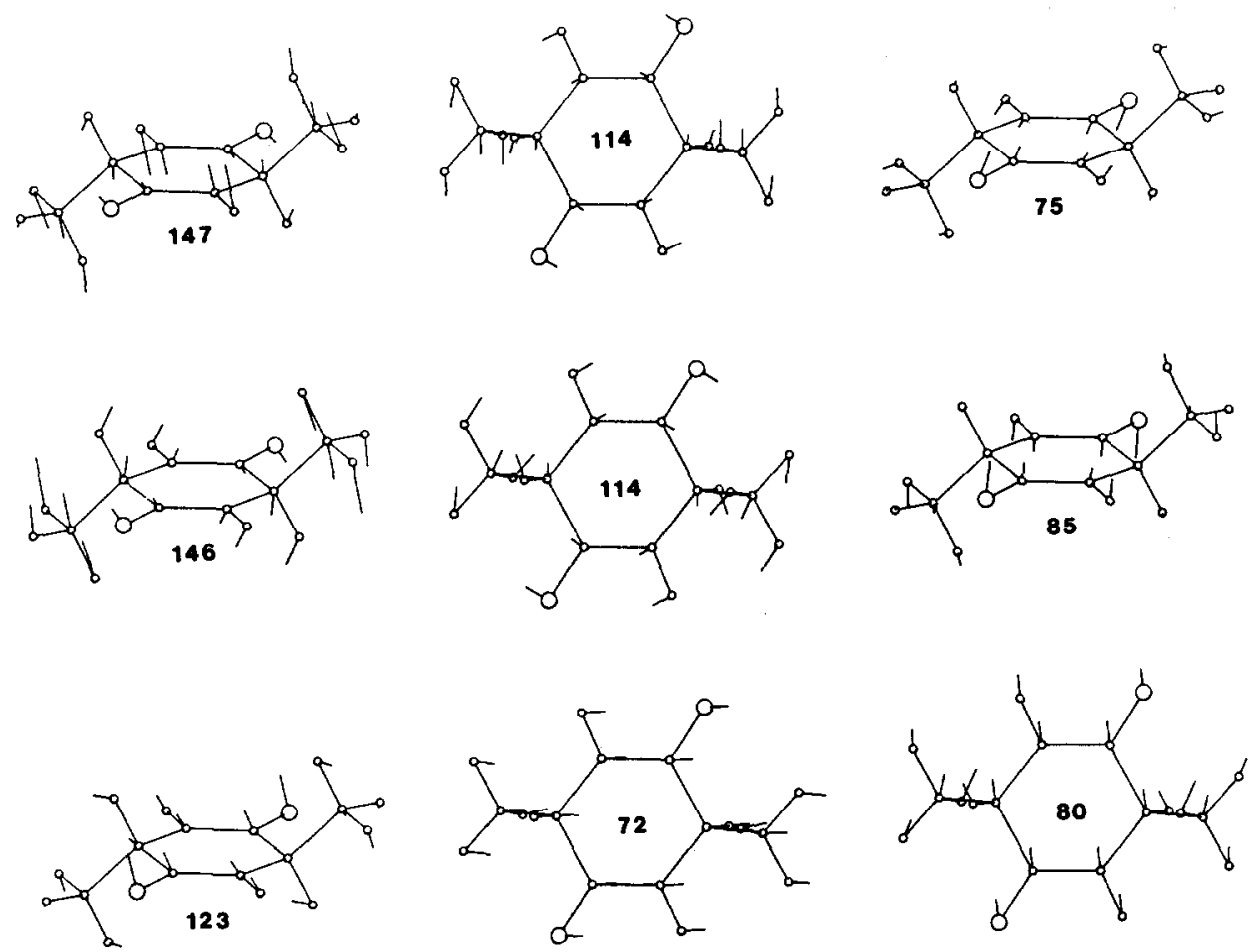

Fig. 17. Lattice modes of form II. Oxygen atoms drawn extra large. Top row: $A_{g}$. Middle row: $B_{q}$. Bottom row: $A_{w}$ and $B_{w}$. Calculated frequencies in $\mathrm{cm}^{-1}$ shown. 
Figures 16 and 17 show the calculated atomic displacements for the lattice modes. For the $z$ librations, about the normal to the ring, the calculated splitting between the in-phase $\left(A_{q}\right)$ and out-of-phase $\left(B_{g}\right)$ modes in both I and $\mathbf{I I}$ is too small, with the $\boldsymbol{A}_{g}$ frequency too high. The $A_{g}$ mode is expected to be more anharmonic than the $B_{q}$ because the diagonal cubic term of the potential energy in the normal coordinates vanishes for all except the totally symmetric species. This term would cause a lowering of the $A_{g}$ frequency. We have found a similar increase in splitting due to a difference in diagonal cubic anharmonicity between the symmetric and antisymmetric $\mathrm{C}=\mathrm{O}$ str modes in the formic acid dimer [20]. Finally we note that the calculated frequencies are not especially sensitive to the $\mathrm{H} \cdots \mathrm{O}$ force constant. When we set this force constant to zero, the largest shift is for the $B_{u}$ mode in $I$, which decreases by only $14 \mathrm{~cm}^{-1}$, while the other modes shift by less than $10 \mathrm{~cm}^{-1}$. Thus, unfortunately, our data cannot be used to determine a more reliable value for the $\mathrm{H} \cdots \mathrm{O}$ interaction.

We conclude our discussion of the spectral assignments with some general remarks. Except for the CO ob mode, the peptide group frequencies, particularly in II, agree well with those found in cyclo(Gly-Gly), with differences that can be related to structural differences. We have not made detailed comparisons of calculated and observed frequencies because we have not refined the force constants transferred from cyclo(Gly-Gly) and alkanes. Nevertheless, Table 2 shows that the agreement is fairly good for most of the modes. The major discrepancies are for the Raman $\mathrm{CO}$ str, the i.r. $\mathrm{CN}$ str, and the $\mathrm{CO}$ ob and ring tor modes. The $\mathrm{CO}$ ob requires new interactions that were not important in cyclo(Gly-Gly), and the torsional force constants for cyclo(Gly-Gly) were less reliably determined because of the sensitivity of the ring tor modes to the intermolecular potential. We should mention that, within the framework of the present unrefined force field, the alkane force constants proved to be more satisfactory, especially in the $900-1400 \mathrm{~cm}^{-1}$ region, than the poly (L-alanine) force fields $[21,22]$ for the $\mathrm{C}^{\alpha} \mathrm{H}^{\alpha}\left(\mathrm{C}^{\beta} \mathrm{H}_{3}\right)$ group. In conclusion, the present set of force constants is a good starting point for refinement of a force field for cyclo(D-Ala-L-Ala).

\section{EFFECT OF HYDROGEN BOND STRUCTURE ON PEPTIDE GROUP MODES}

We have seen above that there are differences in the bands due to the CONH group in I and II. In trying to understand these differences, we first note that since both $\mathrm{CO}$ and $\mathrm{NH}$ groups participate in hydrogen bonds, these modes are likely to be sensitive to the hydrogen bond strength, and that there will be strong intermolecular interactions between peptide groups hydrogen bonded to each other. We next note that the essential structural differences in I and $\mathbf{I}$ are in the hydrogen bond pattern and in the strength of each hydrogen bond. That is, in I the crystal packing is such that each CONH group hydrogen bonds to other groups related to it by a two-fold screw operation, whereas in II the hydrogen bonds are formed between $\mathrm{CONH}$ groups related by the inversion operation. We therefore expect that the factor group splittings of the peptide group modes will tend to be such that in I a large $A-B$ splitting will be seen whereas in II a large $g-u$ splitting will be observed. As we have noted earlier, the dimensions (Fig. 1) of each NH ‥ OC group in I and II indicate that the hydrogen bond in II is stronger than in I. That is, the shorter $\mathrm{N} \cdots \mathrm{O}$ distance, the longer $\mathrm{C}=\mathrm{O}$ bond, the more nearly linear $\mathrm{NH} \cdots \mathrm{O}$ angle, and a $\mathrm{CO} \cdots \mathrm{N}$ angle closer to $120^{\circ}$ all are indicative of a stronger interaction as measured, in particular, by frequency shifts [6]. This difference in hydrogen bond strength would be reflected in a shift between $I$ and $I I$ in the average frequency, over factor group components, of each peptide group mode.

We now discuss to what extent these considerations are borne out for each of the modes of the $\mathrm{CONH}$ group. Except in one instance, we will not attempt here quantitative explanations of the observations.

The mode showing the most striking differences between I and II is the NH str. Of these differences, the roughly $100 \mathrm{~cm}^{-1}$ downward shift of the ND str band (and an estimated $140 \mathrm{~cm}^{-1}$ decrease in the NH str frequency) from I to II is most readily explained as being due to a stronger hydrogen bond in Il. By taking a model system of $N$-methylacetamide hydrogen bonded to a formamide molecule, with $\mathrm{N} \cdots \mathrm{O}$ distance and HNO and CON angles as in I and II, respectively, we can use the method described previously [6] to compute the harmonic force constant of the NH str mode. The frequency shift from I to II given by the scaled STO-3G force constants is $89 \mathrm{~cm}^{-1}$ for the NH str mode and $65 \mathrm{~cm}^{-1}$ for the ND str. Thus, the observed difference in frequency is qualitatively corroborated by $a b$ initio calculations on a model system. Looking at the hydrogen bond dimensions in I and II, we see that while the $\mathrm{N} \cdots \mathrm{O}$ distance in $\mathrm{I}$ is only $0.007 \AA$ longer than in II, which by itself would lead to a calculated shift of less than $2 \mathrm{~cm}^{-1}$ [6], the HNO and CON angles in I are significantly less favorable. That such differences in the angles can result in a frequency shift of over $100 \mathrm{~cm}^{-1}$ in the $\mathrm{NH}$ str mode shows the importance of considering the HNO and $\mathrm{CON}$ angles as well as the $\mathrm{N} \cdots \mathrm{O}$ distance in estimating the strength of a hydrogen bond. This strong dependence of the $\mathrm{NH}$ str frequency on the angles also implies that one should not expect to find a correlation of $\mathrm{NH}$ str frequency with the $\mathrm{N} \cdots \mathrm{O}$ distance. As we have suggested [6], that such a correlation does seem to be observed [23] may be the result of an approximate correlation of NHO angles with $\mathrm{N} \cdots \mathrm{O}$ distance $[24,25]$. A similar explanation probably applies to other types of hydrogen bonds.

We next consider the differences in the fine structure and width of the $\mathrm{NH}$ str mode. An understanding of these differences may be gained by looking at oxalic acid, another molecule that crystallizes in two forms: $\alpha$ - 
oxalic acid with chains formed by $\mathrm{OH} \cdots$ O hydrogen bonds between molecules related by two-fold screw symmetry, and $\beta$-oxalic acid with centrosymmetric hydrogen bonded rings $[26,27]$; the dimensions indicate a stronger hydrogen bond in $\beta$. The i.r. spectra of the $\mathrm{OH}$ str mode in $\alpha$ and $\beta$ [28] resemble closely the NH str bands in I and II respectively. WITKowSKI and WóJCIK [29] have managed to reproduce remarkably well the width and fine structure in both $\alpha$ and $\beta$, as well as the marked narrowing on deuteration, using a quantitative theory of hydrogen bond spectra [30]. In this theory, for an isolated $\mathrm{X}-\mathrm{H} \cdots \mathrm{Y}$ hydrogen bond, anharmonic coupling of the $\mathrm{XH}$ str mode with the low frequency $X \cdots Y$ str mode results in a Franck-Condon progression due to simultaneous excitations of the high and low frequency modes; the spacing between adjacent transitions is determined by the low frequency mode. In crystals, resonant interaction, for example dipole-dipole coupling, between nearby $\mathrm{XH}$ groups causes factor group splittings which further spread out the XH str band and destroy the regularity of the sub-band positions. Further complications are caused by Fermi resonance with overtones and combinations [31]. The difference in complexity in the two forms of oxalic acid arises if one assumes in $\beta$ a stronger anharmonic coupling because of the stronger hydrogen bond and a stronger resonant interaction because of the closeness of the $\mathrm{OH}$ groups in a cyclic ring.

We may expect that a similar explanation applies to cyclo(D-Ala-L-Ala). We have already discussed the stronger hydrogen bond in II, which would lead to a stronger anharmonic coupling with low frequency modes. A theoretical basis for this coupling has been provided by our recent $a b$ initio study [6], which shows large changes in the NH str force constant as the $\mathrm{N} \cdots \mathrm{O}$ distance and $\mathrm{HNO}$ and $\mathrm{CON}$ angles are varied. Lattice modes that involve displacements of these intermolecular coordinates would therefore be expected to be strongly coupled to the NH str mode. It is tempting to infer from the approximate $40 \mathrm{~cm}^{-1}$ spacing of the i.r. sub-band positions in $I$ the frequency of the lattice mode involved. However, we must also consider the $A-B$ splitting, measured to be about $19 \mathrm{~cm}^{-1}$ in the Raman, and the possibility of coupling with more than one lattice mode.

In polypeptides and polyamides with trans peptide units, the narrower and apparently singlet nature of the NH str band may be attributed to the weaker hydrogen bonds, as evidenced by the frequency of about $3250-3300 \mathrm{~cm}^{-1}$, and the smaller resonant interactions between peptide groups that are farther apart than is possible in cis peptides. Nevertheless, the possibility remains that there is unresolved fine structure in the NH str band of polypeptides [17]. We may also conclude that in cis peptides and in amides, a broad, complex NH str band is indicative of a cyclic hydrogen bonded structure.

We conclude our discussion of the NH str mode by mentioning the usefulness of cyclo(D-Ala-L-Ala) and cyclo(Gly-Gly) as models for testing the WITKOWSKI-MARECHAL theory in the case of peptide structures. In I and II we see the effects of different resonant interactions and different hydrogen bond strengths; and in II and cyclo(Gly-Gly) the hydrogen bond geometries are very similar but the low frequency modes are different. In all three structures, our large amount of data and the relatively high symmetry should facilitate analysis, particularly of possible Fermi resonance interactions. And finally, quantitative estimates of the anharmonic coupling parameters may he derived from our study of the variation of the NH str force constant with hydrogen bond geometry [6].

We turn now to the other peptide group modes, all of which show considerably smaller differences between I and II than does the NH str. Table 4 summarizes our results on these modes; where $A-B$ splittings are observed the average frequencies are given, with the splitting in parentheses. Also shown for some modes are the averages over the Raman and i.r. frequencies and the $g-u$ splitting.

Looking at the NH ib mode, we see in I a sizable $\left(40 \mathrm{~cm}^{-1}\right) g-u$ splitting. Much of this is probably a result of intramolecular coupling between the peptide units in each molecule and reflects the relatively delocalized nature of the NH ib mode. Indeed, in II the larger $g-u$ splitting may be ascribed to the additional intermolecular interaction between peptide units in the hydrogen bonded ring. The shift of the mean $g-u$ frequency from $1415 \mathrm{~cm}^{-1}$ in I to $1458 \mathrm{~cm}^{-1}$ in II is a measure of the increase in strength of the hydrogen bond; the change represents a $3 \%$ increase, compared with the approximately $4.3 \%$ decrease of the $\mathrm{NH}$ str frequency from I to II. The ND ib mode is a highly mixed mode and is not expected to show clear trends indicative of the hydrogen bonding.

The well-localized NH ob mode shows clearly the effects of structural differences. The Raman mode in I has a $21 \mathrm{~cm}^{-1} A-B$ splitting whereas that in II has nonc. The i.r. mode in I may have a splitting of about $16 \mathrm{~cm}^{-1}$ if we assign a sharp, distinct band resolved in the low temperature spectrum to the other factor group component. The $g-u$ splitting of $4 \mathrm{~cm}^{-1}$ in I increases to $27 \mathrm{~cm}^{-1}$ in II, where the mean $g-u$ frequency shifts up by $4.5 \%$. Thus, the NH ob is relatively as sensitive to hydrogen bond strength as the NH str, a point emphasized by BANDEKAR and ZUNDEL [32] on the basis of temperature studies of uracil.

Next to the NH str, the CO str mode shows the most interesting differences between I and II. To help understand the changes in this mode, we have to note that it has a large contribution from NH ib. This intramolecular interaction is evidenced by the $19 \mathrm{~cm}^{-1}$ shift from $\mathrm{H}_{2} \mathrm{O}$ to $\mathrm{D}_{2} \mathrm{O}$ solution. Furthermore, in the solid materials, the Raman intensity increases in the ND compounds where the mode is more purely $\mathrm{CO}$ str, and on deuteration the mean $g-u$ frequency decreases by $19 \mathrm{~cm}^{-1}$ in I and by $30 \mathrm{~cm}^{-1}$ in II; the larger magnitudes of these intensity and frequency 
Table 4. Summary of observed frequencies $\left(\right.$ in $\mathrm{cm}^{-1}$ ) of peptide group vibrations in cyclo(D-Ala-L-Ala)*

\begin{tabular}{|c|c|c|c|c|c|c|}
\hline & I & II & $\mathrm{I}-\mathrm{ND}$ & II-ND & $\mathrm{H}_{2} \mathrm{O}$ & $\mathrm{D}_{2} \mathrm{O}$ \\
\hline \multicolumn{7}{|c|}{ NH/ND in-plane bend } \\
\hline Raman & 1395 & 1428 & 1245 & 1244 & \multirow[t]{3}{*}{1404} & \multirow[t]{3}{*}{1228} \\
\hline i.r. & 1435 & 1488 & 1225 & 1234 & & \\
\hline$g-u$ & $1415(40)$ & $1458(60)$ & & & & \\
\hline \multicolumn{7}{|c|}{$\mathrm{NH} / \mathrm{ND}$ out-of-plane bend } \\
\hline Raman & $804(21)$ & 826 & $568(13)$ & 591 & & \\
\hline i.r. & 808 & 853 & 593 & 616 & & \\
\hline$g-u$ & $806(4)$ & $840(27)$ & & & & \\
\hline \multicolumn{7}{|c|}{ CO stretch } \\
\hline Raman & $1654(48)$ & $1658(20)$ & $1637(42)$ & $1618(13)$ & \multirow[t]{3}{*}{1664} & 1645 \\
\hline i.r. & $1664(25)$ & $1674(27)$ & $1643(25)$ & $1654(21)$ & & 1643 \\
\hline$g-u$ & $1659(10)$ & $1666(16)$ & $1640(6)$ & $1636(36)$ & & $1644(2)$ \\
\hline \multicolumn{7}{|c|}{ CO in-plane bend } \\
\hline Raman & 612 & 616 & 599 & 606 & \multirow[t]{2}{*}{610} & \multirow[t]{2}{*}{597} \\
\hline i.r. & $433(9)$ & $453(4)$ & $421(12)$ & $445(8)$ & & \\
\hline \multicolumn{7}{|c|}{ CO out-of-plane bend } \\
\hline Raman & 672 & 661 & 683 & 663 & \multirow[t]{2}{*}{662} & \multirow[t]{2}{*}{668} \\
\hline i.r. & 698 & 692 & 719 & 704 & & \\
\hline \multicolumn{7}{|c|}{ CN stretch } \\
\hline Raman & 1523 & 1516 & 1495 & 1490 & 1517 & 1500 \\
\hline i.r. & 1468 & 1470 & 1459 & 1467 & 1475 & 1466 \\
\hline
\end{tabular}

* Observed splittings in parentheses. Rows labelled " $g-u$ " are averages of Raman and i.r. frequencies with $g-u$ splitting in parentheses.

changes in $\mathbf{I I}$ are because of the higher amount of $\mathrm{NH}$ ib contribution as a result of the higher $\mathrm{NH}$ ib frequency, which in turn arises from the stronger hydrogen bond in II. With this NH ib mixing in mind, then, we observe that in the NH crystals the mean $g-u$ frequency shifts up by $7 \mathrm{~cm}^{-1}$ from I to II, whereas it shifts down by $4 \mathrm{~cm}^{-1}$ in the ND compounds. The explanation is that while a pure CO str mode would decrease in frequency as the hydrogen bond strength increases, a high $\mathrm{NH}$ ib contribution causes the net shift to be upward. We see from the $4 \mathrm{~cm}^{-1}$ shift in the ND compounds that the CO str mode is only slightly sensitive to hydrogen bond strength. On the other hand, the changes in hydrogen bond pattern have significant effects, particularly in the ND compounds, where the $g-u$ splitting is much larger in II but where the $\boldsymbol{A}-\boldsymbol{B}$ splitting is larger in I. This trend is also present in the NH crystals but to a lesser degree for the $g-u$ splitting. The i.r. $A-B$ splittings are not as clear-cut as the Raman splittings, and probably depend on the details of the intermolecular interaction. Thus, as for the NH ob, the extensive data on the $\mathrm{CO}$ str mode confirm very nicely the pattern of splittings expected. Quantitative calculations of the splittings are planned using electrostatic interaction models, in particular dipole-dipole coupling [33] and Coulombic interactions between dynamical atomic partial charges, i.e. atomic charges that are allowed to vary in magnitude as well as position during vibrational motion [20]. We note that representations of van der Waals interactions such as the atom-atom 6-12 potential fail to give any significant splitting of the $\mathrm{CO}$ str mode.
The i.r. CO ib mode shifts up by $4.6 \%$ from I to II and shows a larger $A-B$ splitting in 1. The low frequency of this mode and its mixing with skeletal and side-chain motions probably make it sensitive to other non-bonded interactions as well. The $\mathrm{CO}$ ob is also strongly mixed and is not expected to show trends indicative of hydrogen-bond interactions.

The $\mathrm{CN}$ (or $\mathrm{C}^{\alpha} \mathrm{CN}$ ) str mode does not show any meaningful trends: the Raman mode decreases from $I$ to II but the i.r. mode increases. In any case, it does not seem particularly sensitive to hydrogen bonding. This implies that the trans amide II and 111 modes, which involve $\mathrm{CN}$ str and $\mathrm{NH}$ ib, owe their sensitivity to hydrogen bonding primarily to the $\mathrm{NH}$ ib component.

In summary, of the peptide group modes, the three stretching and bending modes of the $\mathrm{NH}$ bond are extremcly sensitive to the hydrogen bond strength, whereas those of the $\mathrm{CO}$ bond are much less so.

\section{EFFECT OF STRUCTURE ON CH MODES}

Table 5 summarizes the Raman frequencies of the $\mathrm{CH}_{3}$ and $\mathrm{CH}^{\alpha}$ stretch and $\mathrm{H}^{\alpha}$ bend modes in $\mathbf{I}$ and $\mathbf{~ I I}$, together with the values for crystalline $\mathrm{L}$-alanine [14]. We see that while the lower frequency $\mathrm{CH}_{3}$ as mode remains constant, the higher frequency $\mathrm{CH}_{3}$ as increases from I to II. On the other hand, the higher frequency $\mathrm{H}^{\alpha}$ b decreases from L-alanine to I to II, as does the $\mathrm{CH}^{\alpha}$ str. Also observed, but not listed, is a $20 \mathrm{~cm}^{-1}$ shift of one of the i.r. $\mathrm{CH}_{3}$ rock modes from I-ND to II-ND. 
Table 5. Correlation of Raman $\mathrm{C}^{\beta} \mathrm{H}_{3}$ and $\mathrm{C}^{\alpha} \mathrm{H}^{\alpha}$ frequencies with structure

\begin{tabular}{|c|c|c|c|c|}
\hline & & L-Ala & I & II \\
\hline \multicolumn{5}{|c|}{ Observed frequencies (in $\mathrm{cm}^{-1}$ ) } \\
\hline \multirow{2}{*}{\multicolumn{2}{|c|}{$\mathrm{CH}_{3}$ antisymmetric }} & 3001 & 2998 & 3011 \\
\hline & & 2987 & 2984 & 2985 \\
\hline \multicolumn{2}{|c|}{$\begin{array}{l}\text { stretches } \\
\text { splitting }\end{array}$} & 14 & 14 & 26 \\
\hline \multicolumn{2}{|l|}{$\mathrm{CH}^{\alpha}$ stretch } & 2968 & 2914 & 2893 \\
\hline \multirow{2}{*}{\multicolumn{2}{|c|}{$\mathbf{H}^{a}$ bends }} & 1359 & 1323 & 1313 \\
\hline & & 1305 & 1303 & 1300 \\
\hline \multicolumn{2}{|l|}{ splitting } & 54 & 20 & 13 \\
\hline \multicolumn{5}{|c|}{ Structural parameters } \\
\hline \multirow{12}{*}{$\begin{array}{l}\text { Angle from } \\
\mathrm{NC}^{\alpha} \mathrm{C} \text { plane } \\
\text { Dihedral } \\
\text { angles } \\
\text { (L-residue) }\end{array}$} & $\mathrm{C}^{\beta} \mathrm{C}^{\alpha} \mathrm{H}^{\alpha}$ & $110.4^{\circ}$ & $108.2^{\circ}$ & $109.5^{\circ}$ \\
\hline & $\mathrm{CH}^{2}$ & 57.9 & 56.8 & 59.2 \\
\hline & $C^{\alpha} C^{\beta}$ & 52.5 & 51.4 & 50.2 \\
\hline & $\mathrm{OCC}^{\alpha} \mathrm{H}^{\alpha}$ & 44.8 & 59.7 & 64.6 \\
\hline & $\mathrm{OCC}^{\alpha} \mathrm{C}^{\beta}$ & -76.8 & -57.8 & -53.1 \\
\hline & & 110.3 & 107.6 & 109.6 \\
\hline & $\mathrm{C}^{\alpha} \mathrm{C}^{\beta} \mathrm{H}$ & 110.6 & 110.3 & 109.8 \\
\hline & & 110.4 & 112.4 & 108.2 \\
\hline & & 108.9 & 115.2 & 108.3 \\
\hline & $\mathrm{H}^{\beta} \mathrm{C}^{\beta} \mathrm{H}^{\beta}$ & 108.4 & 107.8 & 110.2 \\
\hline & & 108.2 & 102.9 & 110.7 \\
\hline & & 175.2 & -176.4 & -174.6 \\
\hline \multirow{2}{*}{$\begin{array}{l}\text { Dihedral } \\
\text { angles }\end{array}$} & $\mathrm{H}^{\beta} \mathrm{C}^{\beta} \mathrm{C}^{\alpha} \mathrm{H}^{\alpha}$ & 55.5 & 66.3 & 64.2 \\
\hline & & $(-65.1$ & -63.7 & -53.8 \\
\hline
\end{tabular}

As we have seen, the persistence of the differences in the $\mathrm{H}^{\alpha}$ b and $\mathrm{CH}_{3}$ rock modes in solution shows that these changes are due to intramolecular effects. Indeed, we can rule out the possibility that the decrease in the $\mathrm{CH}^{\alpha}$ str frequency in $\mathrm{II}$ is due to formation of an intermolecular $\mathrm{CH}^{\alpha} \cdots \mathrm{O}$ hydrogen bond: the nearest $\mathrm{H}^{\alpha} \cdots \mathrm{O}$ contacts in $\mathrm{I}$ and $\mathrm{II}$ are 2.41 and $2.67 \AA$, respectively, with similarly unfavorable $\mathrm{CH}^{\alpha} \cdots \mathrm{O}$ angles of about $156^{\circ}$ in both. Fermi resonance effects are also not likely because, of the $\mathrm{CH}$ str modes, only the $\mathrm{CH}_{3}$ ss shows evidence in the polarized spectra of being perturbed.

If we then look at the results of normal mode calculations on isolated molecules of I- and II-type conformations, using the same force field and with all $\mathrm{CH}$ bond lengths set to $1.09 \mathrm{~A}$, we find trends inconsistent with what are observed: the $\mathrm{CH}_{3}$ as splitting decreases from I to II, the $\mathrm{H}^{\alpha} \mathrm{b}$ splitting increases from I to II in the Raman and decreases in the i.r., and the $\mathrm{CH}^{\alpha}$ str is unchanged in I and II. To get shifts of these modes in the correct directions, therefore, it is necessary to allow different force constants and probably also different $\mathrm{CH}$ bond lengths in the two molecules. Unfortunately, the X-ray determinations [3-5] cannot tell us whether the $\mathrm{CH}$ bond lengths are different because X-ray $\mathrm{CH}$ bond lengths are highly unreliable [34]. We therefore have to resort to $a b$ initio calculations.

The $\mathrm{CH}^{\alpha}$ bond length and stretching force constant are most easily obtained. We used the STO-3G basis and the procedure described in [6]: keeping the other internal coordinates at their experimental values, we optimized the $\mathrm{CH}^{\alpha}$ bond and then derived the diagonal force constant from the analytical energy gradient. The $\mathrm{CH}^{\alpha}$ str mode is localized, and this procedure is adequate; for the other modes, more extensive optimizations are needed followed by determination of offdiagonal as well as diagonal force constants. We mention first that the SCF energy of conformation II was found to be $3.4 \mathrm{kcal} / \mathrm{mole}$ lower than that of $\mathbf{I}$, which is consistent with the observation that II predominates in solution. (We recall, however, that the crystalline form I is slightly favored according to our crystal-packing calculations.) The equilibrium $\mathrm{CH}^{\alpha}$ bond lengths indeed turn out to be different, $1.0973 \mathrm{~A}$ (I) and $1.0984 \AA$ (II), and the diagonal stretching force constants are $7.055 \mathrm{mdyne} / \AA$ (I) and $7.000 \mathrm{mdyne} / \mathrm{A}$ (II). Using the Jacobian matrix element $\Delta v / \Delta f$ of $312 \mathrm{~cm}^{-1} /($ mdyne $/ \mathrm{A})$, we get a decrease in the $\mathrm{CH}^{\alpha} \mathrm{str}$ frequency from I to II of $17 \mathrm{~cm}^{-1}$. Our result of a frequency change of $17 \mathrm{~cm}^{-1}$ for a $1.1 \times 10^{-3} \AA$ change in $\mathrm{CH}^{\alpha}$ bond length compares well with the value of $16 \mathrm{~cm}^{-1}$ per $10^{-3} \AA$ for deuterium-isolated $\mathrm{CH}$ bonds in $n$-alkanes found by AJILBURY et al. [35] using higher-level $a b$ initio calculations. A scaling factor of 4.6/7.0 for our $a b$ initio force constants must be applied, a value of $4.6 \mathrm{mdyne} / \AA$ being needed to fit the observed frequency of $2893 \mathrm{~cm}^{-1}$ in II; we then get a shift of $11 \mathrm{~cm}^{-1}$. Although this is only half the $21 \mathrm{~cm}^{-1}$ observed shift, we can conclude that the shift is due to a difference in the $\mathrm{CH}^{\alpha}$ force constant in the two conformations. In support of this, the X-ray data show the more nearly axial $\mathrm{C}^{\alpha} \mathrm{C}^{\beta}$ bond in $I$ to be longer than the more nearly equatorial $\mathrm{C}^{\alpha} \mathrm{C}^{\beta}$ bond in II, $1.525 \mathrm{~A}$ versus $1.518 \mathrm{~A}[3,5]$. Since the $\mathrm{CH}^{\mathrm{x}}$ bond in $\mathrm{I}$ is more nearly equatorial, it may be expected to be 
shorter than in II and therefore to have a higher force constant.

It may well be that the difference in the $\mathrm{CH}^{\alpha}$ bond is a result of the total intramolecular environment. Nevertheless, it is useful to look for one or a few structural parameters that might be primarily responsible, as indicated by trends similar to those for the $\mathrm{CH}^{\alpha}$ str and $\mathrm{H}^{\alpha}$ b frequencies. We have listed in Table 5 some parameters involving the $\mathrm{CH}^{\alpha}$ and $\mathrm{C}^{\alpha} \mathrm{C}^{\beta}$ bonds for I and II, and also for L-alanine [36] on the assumption that the charged groups do not introduce significant additional effects. We note first that intramolecular $\mathrm{CH}^{\alpha} \cdots$ O hydrogen bonding is ruled out in view of the $\mathrm{H}^{\alpha} \cdots \mathrm{O}$ distances: $2.65 \AA$ (I) and $2.63 \AA$ (II). The $\mathrm{C}^{\beta} \mathrm{C}^{\alpha} \mathrm{H}^{\alpha}$ angle also does not seem a likely candidate. The angle of the $\mathrm{CH}^{\alpha}$ bond from the $\mathrm{NC}^{\alpha} \mathrm{C}$ plane shows a $2.4^{\circ}$ change from I to II, but the value for L-alanine does not fit the trend. The dihedral angle $\mathrm{OCC}^{\alpha} \mathrm{H}^{\alpha}$ seems promising, with a correct trend and a larger difference between $L$-alanine and $I$ than between $I$ and II. (The variation in the $\mathrm{NCC}^{\alpha} \mathrm{H}^{\alpha}$ angle is similar because of planarity at the $s p^{2}$ carbon.) Accordingly, we computed with the STO-3G basis the $\mathrm{CH}^{\alpha}$ bond length and force constant in a model system in which the comparable dihedral angle was varied, viz. a linear all-trans blocked alanine $\left(\mathrm{CH}_{3}-\mathrm{NH}-\mathrm{C}^{\alpha} \mathrm{H}^{\alpha} \mathrm{C}^{\beta} \mathrm{H}_{3}-\mathrm{C}^{\prime} \mathrm{O}-\mathrm{C}_{1} \mathrm{H}_{3}\right)$ with $\mathrm{C}_{1} \mathrm{C}^{\prime} \mathrm{C}^{\alpha} \mathrm{H}^{\alpha}$ and $\mathrm{C}_{1} \mathrm{C}^{\prime} \mathrm{C}^{\alpha} \mathrm{C}^{\beta}$ angles equal to the $\mathrm{OCC}^{\alpha} \mathrm{H}^{\alpha}$ and $\mathrm{OCC}^{\alpha} \mathrm{C}^{\beta}$ angles in L-alanine, $\mathrm{I}$ and II, respectively. The scaled force constants give shifts of $42 \mathrm{~cm}^{-1}$ from L-alanine to I, and $23 \mathrm{~cm}^{-1}$ from I to II, compared to the observed shifts of 54 and $21 \mathrm{~cm}^{-1}$, respectively. The bond length increases by $2.1 \times 10^{-3} \AA$ from I to II, giving a shift of $10 \mathrm{~cm}^{-1}$ per $10^{-3} \AA$ bond-length change. Thus, there is a significant variation in the $\mathrm{CH}^{\alpha}$ bond length and force constant with the adjacent dihedral angle.

Our findings on the $\mathrm{CH}^{a}$ bond are consistent with spectroscopic and $a b$ initio studies of $\mathrm{CH}$ bonds in hydrocarbons and other molecules $[35,37,38]$. For deuterium-isolated $\mathrm{CH}$ groups in cyclohexane, the equatorial $\mathrm{CH}$ str mode is about $30 \mathrm{~cm}^{-1}$ higher than the axial $\mathrm{CH}$ str mode [39-41]. Ab initio calculations confirm that the equatorial $\mathrm{CH}$ bond is shorter by 1.7 $\times 10^{-3} \AA[35,42]$. Variations in the $\mathrm{CH}$ bond lengths of a methyl group have also been found, an in-plane $\mathrm{CH}$ bond being shorter than the out-of-plane bonds $[35,37,38]$. Finally, calculations on several conformers of $N$-acetyl- $N^{\prime}$-methyl alanyl amide show significant changes in the $\mathrm{CH}^{\alpha}$ bond length (as well as in other parameters) [43]. Our present work extends to peptides these studies on the sensitivity of $\mathrm{CH}$ bonds to molecular environment, providing definitive results on conformations for which X-ray data are available, and also shows the possibility of similar studies of the $\mathrm{CH}$ bend modes. The conformational dependence of the $\mathrm{CH}^{\alpha}$ modes is potentially very useful in studying structure in peptides and polypeptides. If it is difficult to assign the $\mathrm{CH}^{\alpha}$ str mode, the $\mathrm{CD}^{\alpha}$ str may be used.
Turning to the $\mathrm{CH}_{3}$ modes, we find it more difficult to identify a structural parameter that correlates well with the frequencies. According to the angles involving the $\mathrm{C}^{\beta} \mathrm{H}$ bonds, the $\mathrm{CH}_{3}$ group in I seems the most asymmetric, yet the splitting of the $\mathrm{CH}_{3}$ as modes is smaller than in II. The higher degree of asymmetry of the $\mathrm{CH}_{3}$ group in $\mathrm{I}$, resulting in different kinetic couplings between the $\mathrm{C}^{\beta} \mathrm{H}$ bonds, probably explains why our normal mode calculations using a single set of force constants give a larger splitting in I than in II. At the same time it is also likely that the individual $C^{\beta} \mathrm{H}$ bonds are different in length and have different diagonal and interaction force constants. Although a neutron diffraction study of L-alanine [36] shows identical $\mathrm{C}^{\beta} \mathrm{H}$ bond lengths, to within experimental error, spectroscopic and $a b$ initio studies, as mentioned above, have found different $\mathrm{CH}$ bond lengths in methyl groups in various molecules, including L-alanine [44]; in $N$-acetyl- $N^{\prime}$-methyl alanyl amide, in addition, the $\mathrm{C}^{\beta} \mathrm{H}$ bonds were found to vary with conformation [43]. Preliminary ab initio calculations, with limited optimizations, of $\mathbf{I}$ and $\mathbf{I I}$ also indicate different $\mathrm{C}^{\beta} \mathrm{H}$ bond lengths, both within each conformation and between the two conformers. Thus, the differences in the $\mathrm{CH}_{3}$ modes in I and II probably arise from differences in both the $G$ and $F$ matrix elements.

\section{CONCLUSIONS}

We have followed up our previous study of cyclo(Gly-Gly) [1, 2] with a detailed vibrational analysis of cyclo(D-Ala-L-Ala). Our results provide a better understanding of the modes of the cis CONH group in peptides with larger side chains, and complement the large body of work on the trans amide group in peptides and polypeptides [45]

That cyclo(D-Ala-L-Ala) crystallizes in two forms, for which X-ray data are available, presents a rare opportunity to study experimentally the sensitivity of the peptide group modes to hydrogen bonding. Our extensive data have allowed us to correlate the differences in these modes in the two forms with the different hydrogen bond patterns and strengths. Quite unexpectedly, we have also found differences in the $\mathrm{CH}$ modes and have attributed these to the different molecular conformations, a conclusion supported by $a b$ initio calculations on the $\mathrm{CH}^{x}$ stretch mode. In view of the potential importance of a frequency-structure correlation of the $\mathrm{CH}$ modes, further $a b$ initio and experimental work to examine the precise nature of this correlation would be useful.

The significant spectral differences in the two forms imply that it will not be possible to refine a single intramolecular valence force field for both structures. Rather, we think that a more fruitful approach is to develop a molecular mechanics force field [46] that will yield simultaneously both molecular structures as well as the shifts in the peptide group and $\mathrm{CH}$ modes. Such an empirical energy function might incorporate the 
atom-atom potential of MOMANY et al. [12], which we have shown to be very effective in lattice dynamical calculations.

Acknowledgement - This research was supported by National Science Foundation grants DMB-8517812 and DMR8303610. We are indebted to Prof. K. D. KopPLE for providing the sample of cyclo(D-Ala-L-Ala).

\section{REFERENCES}

[1] T. C. CheAm and S. KRImm, Spectrochim. Acta 40A, 481 (1984).

[2] T. C. Cheam and S. Krimm, Spectrochim. Acta 40A, 503 (1984).

[3] J. Sletten, Acta Chem. Scand. A34, 593 (1980). (The $z$-coordinate of oxygen in Table 1 of this reference should read $0.0029(1)$.)

[4] E. Benedetti, P. Corradini and C. Pedone, J. phys. Chem. 73, 2891 (1969).

[5] E. Sletten, J. Am. chem. Soc. 92, 172 (1970).

[6] T. C. Cheam and S. KRImM, J. molec. Struct. 146, 175 (1986).

[7] H. Brockmann and H. Musso, Chem. Ber. 89, part 2 , 241 (1956)

[8] P. Stein, Ph.D. Thesis, University of Oregon (1973).

[9] M. Kobayashi, J. chem. Phys. 70, 4797 (1979).

[10] W. H. MOORE and S. KrIMM, Biopolymers 15, 2465 (1976).

[11] R. G. SNYDER and J. H. SCHACHTSCHNEIDER, Spectrochim. Acta 21, 169 (1965).

[12] F. A. Momany, L. M. Carruthers, R. F. McGuire and H. A. Scheraga, J. phys. Chem. 78, 1595 (1974).

[13] D. M. ByLER and H. Susi, Spectrochim. Acta 35A, 1365 (1979).

[14] H. Sust and D. M. BYLER, J. molec. Struct. 63, 1 (1980).

[15] M. Diem, P. L. Polavarapu, M. OBOOd and L. A. NAFIE, J. Am. chem. Soc. 104, 3329 (1982).

[16] R. DEgEILH and R. E. MARSH, Acta crystallogr. 12, 1007 (1959).

[17] A. Elliott, Proc. R. Soc. A226, 408 (1954)

[18] H. BoutIN and S. YIP, Molecular Spectroscopy with Neutrons, p. 202. MIT Press, Cambridge (1968).

[19] A. Warshel, Comput. Chem. 1, 195 (1977).

[20] J. Dybal, T. C. Cheam and S. Krimm, J. molec. Struct., 159,183 (1987).

[21] J. F. RABOLT, W. H. MoOre and S. Krimm, Macromolecules 10, 1065 (1977).
[22] A. M. Dwivedi and S. KRIMM, Macromolecules 15, 186 (1982); ibid. 16, 340 (1983).

[23] A. LaUtiÉ, F. Froment and A. Novak, Spectrosc. Lett. 9, 289 (1976).

[24] R. Taylor and O. Kennard, Acc. Chem. Res. 17, 320 (1984).

[25] E. N. Baker and R. E. Hubbard, Prog. Biophys. molec. Biol. 44, 97 (1984)

[26] S. B. HENDRICKs, Z. Krist. 91, 48 (1935).

[27] E. G. Cox, M. W. Dougill and G. A. JefFrey, J. Chem. Soc., 4854 (1952).

[28] L. J. Bellamy and R. J. PACE, Spectrochim. Acta 19, 435 (1963).

[29] A. Witkowski and M. Wóscik, Chem. Phys. 21, 385 (1977).

[30] Y. Maréchal and A. Witkowsk1, J. chem. Phys. 48 , 3697 (1968).

[31] M. Wóucik, Molec. Phys. 36, 1757 (1978)

[32] J. BANDEKAR and G. ZUNDEL, Spectrochim. Acta 38A, 815 (1982).

[33] T. C. Chfam and S. Krimm, Chem. Phys. Lett. 107, 613 (1984).

[34] W. C. HAMilton and J. A. IBERs, Hydrogen Bonding in Solids. Benjamin, New York (1968).

[35] A. L. Ajilbury, R. G. SNyder, H. L. Strauss and K. Raghavachari, $J$. chem. Phys. 84, 6872 (1986).

[36] M. S. LehmanN, T. F. Koetzle and W. C. Hamilton, J. Am. chem. Soc. 94, 2657 (1972).

[37] D. C. MCKEAN, J. E. BOGGS and L. SCHÄFER, J. molec. Struct. 116, 313 (1984).

[38] L. SCHÄFER, J. D. EWBANK, V. J. KLIMKOWSKI, K. Siam and C. VAN ALSENOY, J. molec. Struct. (Theochem.) 135, 141 (1986).

[39] J. Caillod, O. Saur and J.-C. Lavalley, Spectrochim. Acta 36A, 185 (1980).

[40] J. S. Wong, R. A. MACPhall, C. B. Moore and H. L. StRaUSS, J. phys. Chem. 86, 1478 (1982).

[41] R. G. SNyder, A. L. Ajilbury, H. L. Strauss, H. L. CASAL, K. M. Gough and W. F. MURPHY, J. chem. Phys. 81, 5352 (1984).

[42] N. S. Chiu, J. D. Ewbank and L. SchäfER, J. molec. Struct. 86, 397 (1982).

[43] J. N. SCarsDale, C. van Alsenoy, V. J. Klimkowski, L. SCHÄFER and F. A. MOMANY, J. Am. chem. Soc. 105, 3438 (1983).

[44] H. Selkers and L. Schäftr, Chem. Phys. Lett. 63, 609 (1979).

[45] S. Krimm and J. BandekaR, Adv. Protein Chem. 38, 181 (1986).

[46] U. BERKERT and N. L. ALLINGER, Molecular Mechanics. American Chemical Society, Washington D.C. (1982). 